\title{
A Review on Edge Computing in Smart Energy by means of a Systematic Mapping Study
}

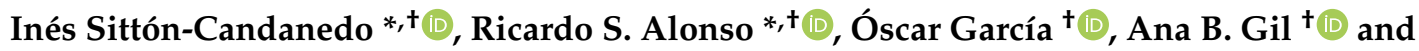 \\ Sara Rodríguez-González ${ }^{+}$(D) \\ BISITE Research Group, University of Salamanca, Edificio Multiusos I+D+i, Calle Espejo 2, 37007 Salamanca, \\ Spain; oscgar@usal.es (Ó.G.); abg@usal.es(A.B.G.); srg@usal.es (S.R.-G.) \\ * Correspondence: isittonc@usal.es (I.S.-C.); ralorin@usal.es (R.S.A.) \\ + These authors contributed equally to this work.
}

Received: 28 October 2019; Accepted: 22 December 2019; Published: 28 December 2019

check for updates

\begin{abstract}
Context: Smart Energy is a disruptive concept that has led to the emergence of new energy policies, technology projects, and business models. The development of those models is driven by world capitals, companies, and universities. Their purpose is to make the electric power system more efficient through distributed energy generation/storage, smart meter installation, or reduction of consumption/implementation costs. This work approaches Smart Energy as a paradigm that is concerned with systemic strategies involving the implementation of innovative technological developments in energy systems. However, many of the challenges encountered under this paradigm are yet to be overcome, such as the effective integration of solutions within Smart Energy systems. Edge Computing is included in this new technology group. Objective: To investigate developments that involve the use of Edge Computing and that provide solutions to Smart Energy problems. The research work will be developed using the methodology of systematic mapping of literature, following the guidelines established by Kitchenham and Petersen that facilitate the identification of studies published on the subject. Results: Inclusion and exclusion criteria have been applied to identify the relevant articles. We selected 80 papers that were classified according to the type of publication (journal, conferences, or book chapter), type of research (conceptual, experience, or validation), type of activity (implement, validate, analyze) and asset (architecture, framework, method, or models). Conclusion: A complete review has been conducted of the 80 articles that were closely related to the questions posed in this research. To reach the goal of building Edge Computing architectures for Smart Energy environments, several lines of research have been defined. In the future, such architectures will overcome current problems, becoming highly energy-efficient, cost-effective, and capacitated to process and respond in real-time.
\end{abstract}

Keywords: smart energy; edge computing; IoT; security; blockchain; systematic mapping study

\section{Introduction}

The term Smart Energy Systems was first introduced in 2012 by Lund et al. [1]. According to Lund et al. [2], the emergence of this concept gave a scientific basis for a paradigm shift, leading to the design of comprehensive strategies that provide solutions to the entire energy system and not just one of its sectors as had been done previously. The term Smart Energy has evolved from the term Smart Grids [3,4]. While Smart Grids were focused solely on the area of electricity, the term Smart Energy also encompasses HVAC (heating, ventilation, and air-conditioning) systems [5], and the intelligent use of energy in Industry 4.0 [6], transportation [7], public buildings [8,9], and homes [10,11]. Smart Energy solutions involve the use of different disruptive technologies, including Artificial Intelligence (such as case-based reasoning systems [12], multi-agent systems) [13], Deep Learning [14]; Distributed 
Ledger Technologies (such as blockchain) [15]; or distributed sensing and actuation technologies such as the Internet of Things (IoT) [3,16].

Regarding the Internet of Things (IoT), its recognition as a paradigm dates back to 2011-2012, when renowned companies and institutions such as Gartner, Forbes, or Wired started using this term to refer to the emerging technology [17]. The Internet of Things implies the connection of different heterogeneous objects, including buildings, machinery, vehicles, and electronic devices, such as sensors and actuators interconnected by means of communication protocols and forming wireless or wired networks [18] to collect information and extract knowledge [19]. Since then, the scope of IoT has spread throughout a great variety of environments and disciplines, including solutions for development of Smart Cities [20,21], Industry 4.0 [22-24], transportation and logistics [25,26], smart homes and hotels $[13,27,28]$ or, more relevant to this research, energy efficiency $[8,29,30]$. IoT provides multiple solutions to each of its application areas. Among the most important functionalities are multiple-communication-protocol management, data processing, real-time information and response, big data storage, and security and data privacy. Nonetheless, the very term IoT implies the heterogeneity introduced by objects, resources or electronic devices, and, for IoT solutions to be effective, it is necessary to develop global architectures capable of coordinating and managing all the resources involved in an IoT environment, as well as the ingestion of data from heterogeneous sources [18].

Edge Computing (EC) [31] represents a paradigm aimed at solving some challenges found in the management of these heterogeneous sources, as well as the acquisition, processing, and transfer of data among massive, interconnected devices [32]. Thanks to the application of Edge Computing techniques, it is possible to prevent an overload of computer processes, as well as, obstructions in the flow of data and the services that are sent or requested to the cloud. This is done by executing computing tasks closer to the IoT devices, that is, directly in the network Edge [33]. Thus, the first phase consists in the management, storage, data analysis, as well as decision making, and it is carried out in multiple Edge Nodes of the IoT network instead of being managed centrally in the Cloud [33,34], improving the response time, security and QoS (Quality of Service) of the services executed in the edge [31]. A basic scheme of an Edge Computing architecture consists of three layers, as follows [6,33] (see Figure 1):

- Layer 1 (IoT + Sensors): The first layer is formed by the IoT devices (sensors, smart-phones, relays, etc.) and the users of the system they interact with. IoT devices are in charge of collecting information and performing operations that involve the use of limited resources;

- Layer 2 (Edge Nodes): Edge nodes are deployed in the second layer. These nodes are responsible for data processing, cache, calculations, and traffic;

- Layer 3 (Cloud Services): The third layer includes Cloud services that have higher computational requirements, such as Machine Learning, Business Intelligence, Big Data analytics, and visualization.

Among the advantages offered by solutions based on Edge Computing over those based exclusively on Cloud Computing solutions, we find [35]:

- Speed: Moving the components responsible for performing data analysis tasks closer to the data source reduces transmission delays and improves service responsiveness;

- Service reliability: Edge Computing solutions deploy local micro data centers for data storage and processing so that user entities reduce their dependence on the availability of cloud services or connectivity to remote servers. Moreover, this reduction in the transfer of data to the Cloud makes it possible to reduce, consequently, the difficulty associated with transmitting such data in a robust and secure manner;

- Cost reduction: The data to be sent to the Cloud is reduced, thus also reducing the costs of transmission, processing, and storage of data in the Cloud.

However, there are some weaknesses that must be considered when implementing Edge Computing based solutions [36], which are described as following: 
- The potential loss of information: It is due to the fact that Edge Computing solutions process and analyze only a subset of the data obtained by the IoT devices locally. In this regard, Cloud Computing technologies provide more powerful resources for advanced applications and Edge nodes often process data that is received, and they don't have to consider entire data stored in the Cloud [37];

- The need for local hardware: Edge Computing solutions require further processing and storage capacity implying additional costs with respect to Cloud-IoT based solutions;

- Security: The addition of devices with such computing capacity implies adding new vectors of potential attacks in the system.

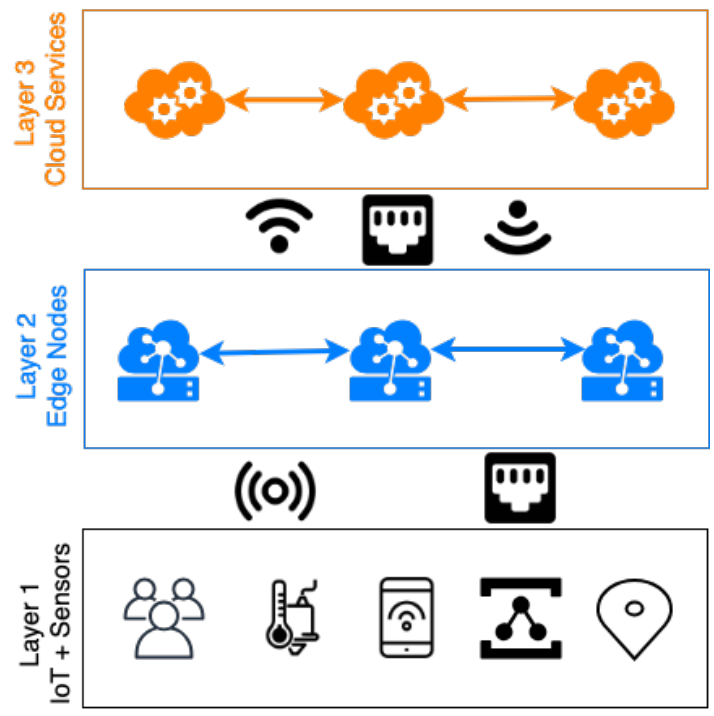

Figure 1. Basic three-layer Edge Computing architecture.

This research work analyzes the state of the art and identifies Edge Computing studies that are oriented to Smart Energy scenarios. It is developed under a methodology of systematic mapping of literature through the guidelines established by Kitchenham et al. [38] and Petersen et al. [39] to perform Systematic Mapping Studies (SMS). Thanks to this type of Study it is possible to perform the categorization of existing studies in a specific research area through a scheme and structure indicating the frequency with which research in that area is carried out, showing the results obtained visually as a map [40].

The rest of this paper is structured as follows: Section 2 analyzes the state-of-the-art reviews and surveys performed by other authors in the fields of Edge Computing and Smart Energy. Then, Section 3 details the Planning, Development and Report stages of a Systematic Mapping Study methodology proposed by Petersen et al. [39]. This method has been employed to conduct the research presented in this article. Then, Section 4 presents the results of the Report stage of the conducted systematic mapping study of Edge Computing in Smart Energy scenarios. These results are analyzed in-depth in Section 5, including a description of the different reviews, architectures, frameworks, methods, and models found in the research area under study. Finally, conclusions are presented in Section 6.

\section{Related Work}

An SMS is a methodology that helps researchers identify, analyze, and classify a field of interest [41]. This methodology is widely applied in medical research and over the last few years has become common in computer science, especially in the area of software engineering [42]. The main objective of these studies is to determine the coverage of a concrete research field by analyzing the frequency of publications for multiple categories in the form of a scheme. These schemes can be tailored to focus on specific research topics [39].

More concretely, SMS studies Heinz [43] aim to: 
- Identify and review the principal studies in the area of interest;

- Describe the methodology and results of principal reports;

- Develop a classification scheme;

- Build a classification scheme and structure a field of interest by categories;

- $\quad$ Structure the research topic, the type of research performed and the results obtained;

- Identify the frequencies of publications for each category;

- Define the coverage of the research field;

- Combine the obtained results to contribute to the general progress of the research field;

- Visualize the results in the form of a mapping schema.

In computer science, systematic literature mapping studies were first conducted in the area of software engineering. They provide researchers with a comprehensive understanding of their research field and help refine the research questions and topics of interest. SMSs have been performed in more specific research areas, it is the case of software engineering. This is the case of this work, in which the authors' interest is focused on the use of Edge Computing in Smart Energy scenarios. Regarding this research area, some related works have been identified and are presented below.

Sittón-Candanedo et al. [6] presented an in-depth review of Edge Computing architectures, focusing on the so-called Reference Architectures (RA). Firstly, they conducted an analysis of eight different definitions of Edge Computing, this has provided context for their study. Then, the authors underscored the advantages of Edge Computing systems and provided an overview of the four main RA in the literature; those proposed by the Edge Computing Consortium [44], the Intel-SAP [45], the FAR-Edge Project [46], and the Industrial Internet Consortium for Industry 4.0 [47]. Furthermore, the overview included a detailed description of all the components of the architectures and gave the application scenarios of each one: smart water, connected assets and logistics, production plant and electric submersible pumps, following the order in which they were presented above. Finally, the researchers presented an architecture that integrated the different components of the analyzed RAs, called Global Edge Computing Architecture.

Another interesting study is the one conducted by Shah et al. [48]. In their work, the authors reviewed the different energy optimization techniques employed in Smart Building environments that make use of IoT solutions. Their study, according to the authors, aims to identify algorithms and techniques for optimized energy use and scheduling, identify Edge Computing and fog computing techniques, as well as technologies used in Smart Home environments and their comfort parameters. Shah et al. (2019) reviewed and filtered 3800 papers published since 1996 until 2018. All those papers proposed solutions for the Smart Buildings scenario, including genetic algorithms for energy optimization, edge and fog computing, energy scheduling, and IoT. Out of the 3800 papers, only 115 were selected as primary studies and the 56 more relevant were analyzed in detail.

Another relevant state-of-the-art research is that of Fei et al. [49]. In this case, the authors have performed a systematic study of Machine Learning techniques for cloud and fog computing in IoT and Cyber-Physical Systems (CPS). The researchers addressed the problem from multiple perspectives but dedicated a large part of their study to time complexity because it was essential when deploying the techniques in the architecture. Among the numerous machine learning techniques are artificial neural networks, support vector machines, Bayesian networks, decision trees, clustering, etc. The authors also identify their main application in CPS, such as Smart Grid, Intelligent Transportation Systems and Manufacturing-Industry 4.0, and match every technique with its specific field of application.

Regarding IoT systems, Portilla et al. [50] described and analyzed the structure of IoT systems according to the four computing paradigms: Cloud, Fog, Edge, and Extreme Edge. They focused especially on the extreme edge concept, outlining its implementation requirements and options, which vary depending on the environment in which they are implemented and the type of devices that make it up. In this case, the authors analyze nine different solutions with the main to identify the requirements for IoT developments in real environments.

Gilbert et al. [51] performed a systematic literature review of edge and fog computing for Smart Grid applications. The authors explored the application of these two paradigms in smart 
grid applications. To this end, they performed an in-depth analysis of a total of 70 papers out of the 830 identified initially. The review has been conducted by answering three research questions: "What are the current edge computing requirements for smart grid applications? Which smart grid applications use Edge Computing? What are the challenges of using Edge Computing in smart grid applications?"

The research of Väänänen and Hämäläinen [52] analyzed the requirements for energy-efficient Edge Computing. The authors identified multiple challenges when applying edge and fog computing in energy efficiency applications. Basing themselves on their analysis of 35 study, they identify important challenges such as reducing energy consumption in wireless sensor networks; data compression methods for loss reduction in edge devices; use of wireless technologies for efficient energy use in IoT; as well as issues related to communication protocols, security, and privacy.

Within Edge Computing, Mao et al. [53] focused on mobile communication which is a more granular area. The authors performed a survey of mobile Edge Computing, focusing on the transmission and management of computing resources. By analyzing more than 200 related studies, the researchers identified several issues and challenges, such as system deployment, cache enablement, mobility management, environmental influence, security, and privacy. The authors also drew comparisons between mobile Edge Computing and mobile cloud computing systems, providing detailed descriptions of computation and communication models, resource management and future lines of research in mobile Edge Computing. Finally, the authors also introduced the state of the art literature on the standardization of mobile Edge Computing and several application scenarios.

Within the field of energy, Smart Grids are one of the most commonly addressed topics in the literature. Thus, Samie et al. [54] presented an overview of the different architectures and solutions in this matter. The chapter focused on Smart Home environments and identified the advantages of Edge Computing in terms of self-supporting, security and privacy. Given that the authors focused on a specific scenario, during the implementation of the IoT system, the type of IoT devices (low-power, low-cost, small size, etc.), network issues (bandwidth, latency, scalability, etc.) and the application requirements (privacy, response time, low maintenance, etc.) were considered. Moreover, they studied information processing in Smart Grids taking into account all the stakeholders, such as suppliers, customers or cloud service providers. A total of nine solutions are analyzed and a use case for Home Appliance Management is presented.

Finally, Wlodarczak [55] scrutinized the technologies that enable the implementation of Smart City solutions. The chapter provides an extended definition of Smart Cities, which includes smart mobility, energy, and users. The work intends to encompass different smart areas that form part of the Smart City environment, such as smart people, smart government, smart economy, smart living, smart traffic, and smart environment. The conducted research also reviewed the use of IoT focusing on standard architectures, communication, and data analysis.

On the whole, the reviews described above have focused on state-of-the-art solutions for topics such as:

- The optimization of energy consumption in smart homes and buildings;

- IoT infrastructures integrating technologies such as cloud, fog, and Edge Computing;

- The application of Edge-Fog Computing in Smart Grids;

- Energy efficiency using Edge Computing;

- IoT energy solutions for Smart Cities.

Only the review presented by Shah et al. [48] has been done using the SMS technique, its contribution is important because it identifies the main solutions for optimizing energy consumption in intelligent buildings. However, there is a lack of a systematic literature analysis regarding Edge Computing solutions for Smart Energy environments.

Therefore, the present research contributes to the state of the art in that it gives structure to the research in the area of Edge Computing and Smart Energy, by means of the systematic mapping method. Moreover, the analysis results have been used to propose future lines of research in this field. 


\section{Research Methodology}

Similar to the research conducted by Tofan et al. [56], Montalvillo and Díaz [57], we conducted an SMS on the basis of the phases and methodology proposed by [39]. The process consisted of Planning, Development, and Report. These three phases will be detailed in the following subsections.

\subsection{Planning}

Three activities have been considered for the planning of our SMS: motivation/research gap, objective, and research questions. We have used the works of Kitchenham et al. [38], Petersen et al. [39], Montalvillo and Díaz [57] as reference.

\subsubsection{Motivation and Relevance}

The motivation behind this SMS is the evolution and adoption of Edge Computing in several research fields. Currently, Edge Computing has been used in IoT scenarios through its inclusion in reference architectures for Industry 4.0. [44-47]. The main goal of this study is to review state-of-the-art literature that proposes the use of Edge Computing in Smart Energy environments. Likewise, we identify future lines of research in the area of Edge Computing and Smart Energy.

\subsubsection{Objective}

Over the last few years, the rate of EC penetration has accelerated due to the rising demand for real-time processing and analysis of critical data from the edge of the network. The main players in the process are IoT devices, Big Data, the emerging 5G, and users. Edge Computing has until now been mostly associated with Industry 4.0, however, its application to other smart scenarios such as cities, agriculture, energy, home, or health is gaining popularity [58]. Due to the importance of Edge Computing, the main objective of this work is to identify the trends, evolution and principal research regarding the adoption of Edge Computing in Smart Energy scenarios and obtain a comprehensive overview of current research in Edge Computing and Smart Energy.

\subsubsection{Research Questions}

The research questions that will allow us to find the evidence on which our systematic mapping study is based are the following:

- What asset types have been reported about Edge Computing in Smart Energy scenarios?

- How Smart Energy scenarios benefit from the implementation of Edge Computing architectures?

By answering these questions, it will be possible to categorize existing works until 4 June 2019 and to present visual maps in the results section.

\subsection{Development of the Study}

This phase involves performing all the tasks associated with conducting a Systematic Mapping Study. First, the search strategy is defined to obtain relevant papers and the inclusion/exclusion criteria are defined and used to filter the studies until the most relevant studies are obtained and used to perform the mapping.

\subsubsection{Search Strategy}

To conduct an SMS, it is important to build a search strategy and define search strings. The authors adopt PICO (Population, Intervention, Comparison, and Outcomes) that has been initially proposed in Kitchenham et al. [38] and applied in Petersen et al. [39] and their guidelines to conduct the SMS. PICO is suggested to build search strings from keywords in research questions.

- Population: in this SMS, populations are the research papers; 
- Intervention: this term refers to solutions, architectures, or models implemented with Edge Computing in Smart Energy scenarios;

- Comparison: We compare the different types of assets and investigations found;

- $\quad$ Outcomes: Not applicable to this SMS.

After the PICO approach, our keywords are Edge Computing and Smart Energy. Other keywords were considered smart grid, smart consumption, green energy, and energy optimization. These keywords were included to expand the results obtained in the searches, because a first simple search string was defined using only as keywords: Edge Computing and Smart Energy. The results obtained did not exceed 36 articles, so the authors decided to extend the search string by increasing the number of keywords. With this second search string, the total number of articles was 117. With this result, it was decided to further expand the search string by including the concept of "Edge Computing" and "edge cloud computing", as well as smart grid, smart consumption, green energy, and energy optimization, considering that the latter are linked to "Smart Energy" scenarios. The search strings were built for the following databases: Web of Science, Scopus, and Springer. The deadline for the article search was 4 June 2019. In Table 1 the search strings are detailed.

Table 1. Search string designed for database search.

\begin{tabular}{|c|c|}
\hline Data Base & Search String \\
\hline Web of Science (WS1) & (TS=((“Edge Computing*”) AND (“Smart Energy") $))$ \\
\hline Web of Science (WS2) & $\begin{array}{l}\text { (TS=((“Edge Computing") AND (“Smart Energy" OR "smart gird" OR } \\
\text { "smart consumption" OR "green energy" OR "energy optimization" ))) }\end{array}$ \\
\hline Web of Science (WS3) & $\begin{array}{l}\text { (TS=(("Edge Computing" OR "edge cloud computing") AND ("Smart } \\
\text { Energy" OR "smart gird" OR "smart consumption" OR "green energy" } \\
\text { OR "energy optimization" ))) Bases de datos= WOS, CCC, DIIDW, KJD, } \\
\text { MEDLINE, RSCI, SCIELO Período de tiempo=Todos los años Idioma de } \\
\text { búsqueda=Auto }\end{array}$ \\
\hline Scopus (SC1) & TITLE-ABS-KEY ( “Edge Computing” ) AND ( “Smart Energy*”) \\
\hline Scopus (SC2) & $\begin{array}{l}\text { TITLE-ABS-KEY ( “Edge Computing*") AND ( “Smart Energy" OR } \\
\text { "smart gird"” OR “smart consumption*" OR "green energy*" OR “energy } \\
\text { optimization*") }\end{array}$ \\
\hline Scopus (SC3) & $\begin{array}{l}\text { TITLE-ABS-KEY ( "Edge Computing*" OR "edge cloud computing") } \\
\text { AND ( "Smart Energy*" OR "smart gird*" OR "smart consumption*" OR } \\
\text { "green energy*" OR "energy optimization*" ) }\end{array}$ \\
\hline Springer (SP1) & (“Edge Computing”) AND (“Smart Energy*”) \\
\hline Springer (SP2) & $\begin{array}{l}\text { ("Edge Computing*") AND ( "Smart Energy" OR "smart gird*" OR } \\
\text { "smart consumption*" OR "green energy*" OR “energy optimization*") }\end{array}$ \\
\hline Springer (SP3) & $\begin{array}{l}\text { ("Edge Computing*" OR "edge cloud computing" ) AND ( "Smart } \\
\text { Energy*" OR "smart gird*" OR "smart consumption*" OR "green energy" } \\
\text { OR "energy optimization*") }\end{array}$ \\
\hline
\end{tabular}

According to Table 1, three search strings were designed for each database to increase the number of articles obtained in the preliminary results.

\subsubsection{Inclusion/Exclusion Criteria}

In their guide, Petersen et al. [39] pointed to the importance of establishing the characteristics that the identified studies must meet in order to be included or excluded from a systematic mapping study. Using this guide as a basis, the following inclusion and exclusion criteria were considered when selecting a paper:

- $\quad$ Peer-reviewed book chapters and papers published in journals or conferences;

- $\quad$ Studies published between 2015 to June 2019;

- $\quad$ Studies in the field of Edge Computing and Smart Energy.

The following exclusion criteria have been established: 
- EC1: Duplicated papers;

- EC2: Papers that do not address Smart Energy and Edge Computing;

- EC3: Those papers in which the authors doubt if they contribute or not with solutions that incorporate Edge Computing in Smart Energy scenarios.

It is important to mention that the papers are excluded if they do not meet the inclusion criteria established in the methodology for the development of the SMS.

\subsection{Mapping Report}

The mapping report includes the mapping scheme with the data extraction by asset and research type. During the filtering process, we doubted the relevance of 12 of the papers. To strengthen the criteria for inclusion-exclusion of articles, the support of three researchers was requested for evaluation by experts, specifically, this allows maintaining neutrality and objectivity in the process of selection and rejection of articles related to the subject of the review. These researchers are not the authors of the articles being analyzed, therefore, our gratitude extends to them at the end of the article in the Acknowledgments section. Table A1 shows the full mapping report and lists all principal studies.

\subsubsection{Filtering Studies}

A total of 354 related studies were found in the first step. To filter those studies, the previously defined inclusion and exclusion criteria have been defined. The filtering process was conducted by the first author. The papers that have been selected met all the inclusion criteria and none of the exclusion criteria. The first author consulted the rest of the co-authors in cases where it was not clear whether an article should be included or excluded. The authors have requested support from other researchers to resolve disagreements between them when needed. Those researchers are mentioned in the Acknowledgment section.

\subsubsection{Classification Process}

Once the filtering process has been completed, the obtained articles were classified on a spreadsheet into the following categories: Author, Title, Year, Type of Publication, Research Type, Evolution Activity and Asset Type. The Type of Publication is divided into Journal, Conference Papers and Book Chapters. In the Research Type category, studies are classified into: Conceptual, Experimental, Validation. The evolution activity allows one to classify the articles determining if only analysis is carried out or if the proposed solution is implemented. The Asset Type consists of the main contribution of the article: an architecture, method, model, framework, or platform. There is a set of articles that can contain two or more research types or asset types. In those cases, a single record containing the categories is made to avoid duplicity in the data. The results of the development of this process are detailed in Table A1.

\subsubsection{Validation of the Systematic Mapping Study}

Petersen et al. [39] established a rubric to validate and evaluate Systematic Mapping Studies. The evaluation rubric is formed by 26 activities that should be performed when conducting an SMS. According to the authors, a well-developed SMS performs at least $33 \%$ of these activities. This means that a minimum of 9 activities must be performed to obtain a mid-quality SMS. As established in Petersen's Guidelines, to measure the validity of an SMS , it is necessary to calculate the ratio between the number of activities performed in an SMS and the 26 activities proposed in the guidelines. Figure 2 shows the three phases in which this mapping was divided: Planning, Development, and Report, as well as a list of activities that have been performed to ensure the validity of our study, all of them based on the Petersen et al. [39] evaluation rubric. Likewise, the SMS has been developed by applying 16 of the 26 activities established by the Petersen rubric. The ratio obtained is $61 \%$. Therefore, the SMS is above the established median quality according to Montalvillo and Díaz [57]. 


\begin{tabular}{|c|c|c|c|}
\hline & & Applied (Yes $=\checkmark \&$ No $=x$ ) & Defined in... \\
\hline Planning & $\begin{array}{l}\text { Need for the map } \\
\text { 1. Motivate the need and relevance. } \\
\text { 2. Define objective and quiestions. } \\
\text { 3. Consult with target audience to define questions. }\end{array}$ & $\begin{array}{l}\text { Need for the map } \\
\text { 1. } \checkmark \\
\text { 2. } \checkmark \\
\text { 3. } x\end{array}$ & $\begin{array}{l}\text { Introduction, Related Work and Methodology } \\
\text { 1. Introducction, Related work and Methodology (Sections } 1,2 \text { \& 3) } \\
\text { 2. Objective (Section 3.2.1.) and Research Questions (Section 3.1.3) } \\
\text { 3. }\end{array}$ \\
\hline \multirow[t]{2}{*}{ Development } & $\begin{array}{l}\text { Study identification /Choosing search strategy } \\
\text { 4. Snowballing. } \\
\text { 5. Manual. } \\
\text { 6. Conduct database search. } \\
\text { Develop the search } \\
\text { 7. PICO. } \\
\text { 8. Consult librarians or experts. } \\
\text { 9. Iteratively try finding more relevant papers. } \\
\text { 10. Keywords from know papers. } \\
\text { 11. Use standards, encyclopedias and thesaurus. } \\
\text { Evaluate the search } \\
\text { 12. Test-set of known papers. } \\
\text { 13. Expert evaluates results. } \\
\text { 14. Search web pages of key authors. } \\
\text { 15. Test-retest. } \\
\text { Inclusion-Exclusión } \\
\text { 16. Identify objective criteria for decisión } \\
\text { 17. Add additional reviewer, resolve disagreements } \\
\text { between then when needed. } \\
\text { 18. Decision rules. }\end{array}$ & $\begin{array}{l}\text { Study identification /Choosing search strategy } \\
\text { 4. } x \\
5 . \checkmark \\
6 . \checkmark \\
\text { Develop the search } \\
\text { 7. } \checkmark \\
\text { 8. } x \\
9 . \checkmark \\
\text { 10. } \checkmark \\
\text { 11. } x \\
\text { Evaluate the search } \\
\text { 12. } \checkmark \\
\text { 13. } x \\
\text { 14. } x \\
\text { 15. } x \\
\text { Inclusion-Exclusión } \\
\text { 16. } \checkmark \\
\text { 17. } \checkmark \\
\text { 18. } \checkmark\end{array}$ & $\begin{array}{l}\text { Methodology } \\
\text { 4. } \text { 5evelopment, Search Strategy (Section3.2. \& 3.2.1) } \\
\text { 6. Search strategy (Section 3.2.1.) } \\
\text { Development the study } \\
\text { 7. PICO.(Section 3.2.1.) } \\
\text { 8. } \\
\text { 9. Section 3.2.1. } \\
\text { 10. Search Strings, Table 1. } \\
\text { 11. } \\
\text { Test-set references } \\
\text { 12. } \\
\text { 13. } \\
\text { 14. } \\
\text { 15. } \\
\text { Inclusion-Exclusión } \\
\text { 16. Inclusion/Exclusion criteria (Section 3.2.2.) } \\
\text { 17. External research help authors to resolve disagreements } \\
\text { between them (Section 3) } \\
\text { 18. Discussion with all authors (Section 3.2.3.) }\end{array}$ \\
\hline & $\begin{array}{l}\text { Extraction process } \\
\text { 19. Identify objective criteria for decision. } \\
\text { 20. Obscuring information that could bias. } \\
\text { 21. Add additional reviewer, resolve disagreements } \\
\text { between then when needed. } \\
\text { 22. Test-retest. }\end{array}$ & $\begin{array}{l}\text { Report the mapping \& Methodology } \\
\text { 19. } \checkmark \\
20 . \times \\
21 . \checkmark \\
\text { 22. } \times\end{array}$ & $\begin{array}{l}\text { Report the mapping \& Methodology } \\
\text { 19. Classification process (Section 3.3.2.) and Figure } 1 . \\
\text { 20. } \\
\text { 21. External researchers help authors to resolve disagreements } \\
\text { between them. (Section 3.2.2.) } \\
\text { 22. }\end{array}$ \\
\hline Report & $\begin{array}{l}\text { Classification scheme } \\
\text { 23. Research type. } \\
\text { 24. Research method. } \\
\text { 25. Venue type. } \\
\text { Validity discussion } \\
\text { 26. Validity discussion / limitations provided. }\end{array}$ & $\begin{array}{l}\text { 23. } \checkmark \\
24 . x \\
25 . v \\
26 . v\end{array}$ & $\begin{array}{l}\text { 23. Methodology (Section 3). } \\
\text { 24. } \\
\text { 25. Figure 3. Mapping study (Section 4) } \\
\text { 26. Appliying Petersen et al (2015) evaluation rubric (Section } 3.3 .3 \text {.) }\end{array}$ \\
\hline
\end{tabular}

Figure 2. Activities from Petersen et al. [39] evaluation rubric conducted in this systematic mapping study (SMS). 


\section{Mapping}

This section includes the Systematic Mapping Study report. First, in Table 2, the authors list the number of papers obtained in every search per database. For each of the databases: Web of Science, SCOPUS, and SPRINGER, a first simple search string was defined using only Edge Computing and Smart Energy as keywords, the obtained results did not exceed 36 articles, so the authors decided to extend the search string by increasing the number of keywords, with a, second search string detailed in Table 1. The total number of article results was 117. It was then decided to extend the search string even further by broadening the concept of "Edge Computing" and including "edge cloud computing", considering that in the first search results, the concept of "edge" is linked to the cloud within the group of keywords defined by the authors. The application of the last search chain resulted in 354 papers which were reviewed and filtered by applying the inclusion and exclusion criteria.

Table 2. Preliminary paper results per database.

\begin{tabular}{ll}
\hline Data Base & Search Results \\
\hline Web of Science (WS1) & 1 \\
Web of Science (WS2) & 14 \\
Web of Science (WS3) & 15 \\
Scopus (SC1) & 35 \\
Scopus (SC2) & 94 \\
Scopus (SC3) & 97 \\
Springer (SP1) & 0 \\
Springer (SP2) & 9 \\
Springer (SP3) & 89 \\
\hline Total & 354 \\
\hline
\end{tabular}

The filtering process of the studies selected for the mapping report. This process is illustrated in this section in Figure 3.

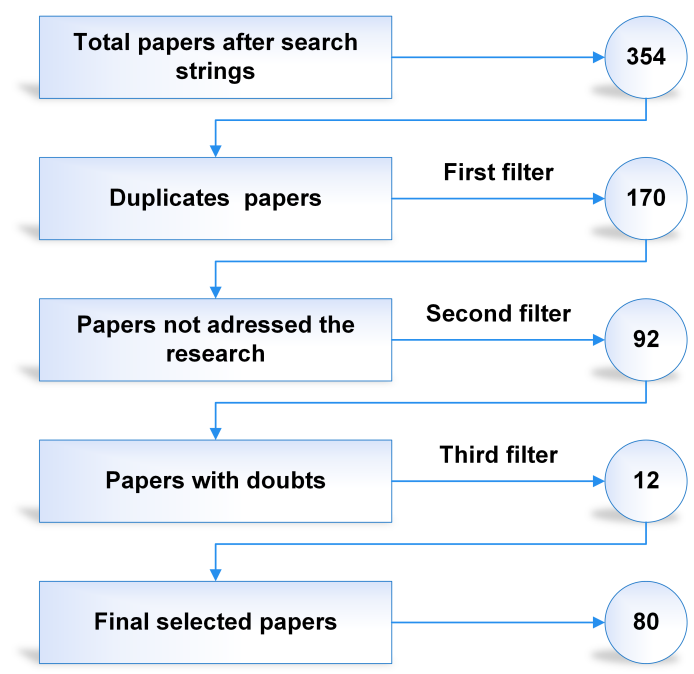

Figure 3. Filtering process to obtain final studies for review.

In Figure 4, three dimensions have been considered: Asset type, research type, and publication type. The results allow us to identify that out of the 80 relevant papers, approximately $43.8 \%$ do not include an architecture, framework, method, or model as their contribution, instead, they perform an exhaustive review of concepts or of the state of art. 
Publication type

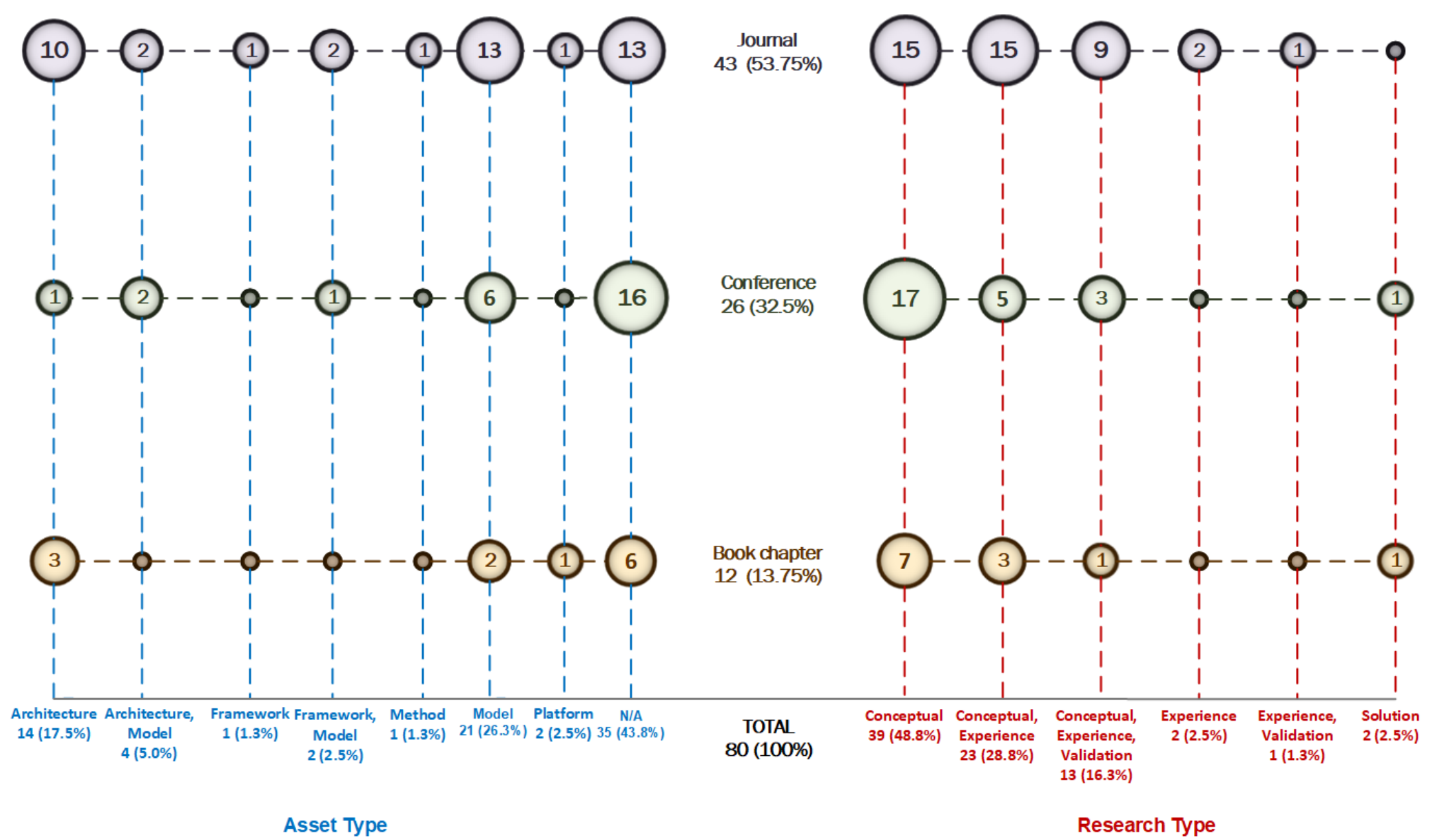

Figure 4. Mapping "Publication type" according to two dimensions: "Asset type" and "Research type". 


\section{Results}

During the development of the systematic mapping study, as explained in Figure 4, 48.8\% of the selected papers correspond to a type of conceptual review-based research. The authors consider the following to be the most important research:

Shah et al. [48] presented a major review of fog and Edge Computing techniques for optimizing energy consumption in smart buildings and smart homes. They also included a systematic mapping study for energy optimization techniques and how edge and fog computing is applied in smart homes and grids.

Fei et al. [49] presented physical Cyber Systems and reviewed machine learning techniques that can be developed in a cloud-fog-Edge Computing architecture. However, the article also focuses on the limitations of Edge Computing, especially in terms of its storage and processing capacity.

Portilla et al. [50] structured the research in the area of the Internet of Things and the extreme of the network. The authors presented a general review of the following concepts: The Internet of Things, the cloud, fog, edge, and extreme edge. A section is included in which Edge Computing and its incorporation in industrial scenarios are described in more detail, as well as a review of its challenges and requirements for the development of applications and solutions in which edge devices are deployed at the edge of the network.

Gilbert et al. [51] conducted a systematic review of the literature with the aim of identifying the requirements, challenges, and benefits of incorporating edge or fog computing in the development of smart grid applications. They used 70 relevant studies. They have shown the rise in the development of applications or solutions that integrate edge or fog computing in smart grids [51].

Väänänen and Hämäläinen [52] defined the concepts of edge, fog, cloud and cloud, however, the authors dedicated an entire section to identifying the advantages of Edge Computing. The authors analyzed the benefits of Edge Computing from the perspective of energy efficiency, security, and privacy. The article also includes a brief review of the protocols for wireless IoT sensor networks.

Mao et al. [53] from the perspective of the disruptive 5G technology, the authors analyzed the concept of Mobile Edge Computing (MEC) by conducting a survey and by comparing these systems and the previous MCC (Mobile Cloud Computing), where data traffic was centralized in the cloud. The article also included a review of characteristics, challenges, security aspects, and communication models of Edge Computing.

Samie et al. [54] used the concept of the Internet of Things as a starting point and its requirements for the implementation of Edge Computing. The authors highlighted the importance of IoT applications in Smart Grid scenarios and also reviewed the proposed architectures for Edge Computing in smart grid.

Sittón-Candanedo et al. [6] reviewed the main Edge Computing concepts and authors and four reference architectures proposed by the Edge Computing Consortium, Intel-SAP, the FAR-Edge Project and the Industrial Internet Consortium for Industry 4.0. On the basis of their review, the authors proposed a new Global Edge Computing Architecture.

Khanna et al. [59] reviewed in this work various architectures and Internet of Things frameworks that have been developed for smart buildings. The advantages, disadvantages, requirements, components, and challenges have been identified. In this paper, the authors considered Edge Computing as an important component in IoT architectures that are developed for smart building scenarios.

Wlodarczak [55] reviewed smart concepts such as cities, people, government, economy, focusing on their link with the Internet of Things and how the IoT has caused the rise of technologies such as fog or Edge Computing. A review of reference IoT architectures has been conducted, and smart cities and energy consumption in urban environments are presented as future challenges.

We did a content analysis of the papers categorized as "reviews" by means of a keyword cloud. The objective was to identify the group of terms that have been the most prominent in the research on Smart Energy environments, during the period covered by the systematic mapping study. The keyword cloud results are shown in Figure 5, in which it is possible to observe that the main terms are: Internet 
of Things and Edge Computing, while less relevant terms include: Smart Energy, Smart Home, Smart Buildings, and Fog Computing.

This shows that Internet of Things (IoT), is one of the most relevant keywords in these articles, however, fundamental aspects of this environment such as sensors, data security, and Blockchain technology do not have the same importance in these publications. The same applies to the concept of smart grids, which is an important part of the context of Smart Energy and no research has been identified that present solutions with Edge Computing for this field.

The essence of the results section is to develop a mapping report answering the authors' research questions, analyzing the main types of studies that have been developed and identifying the research gaps. The answers to two of the research questions are detailed in the next subsections.

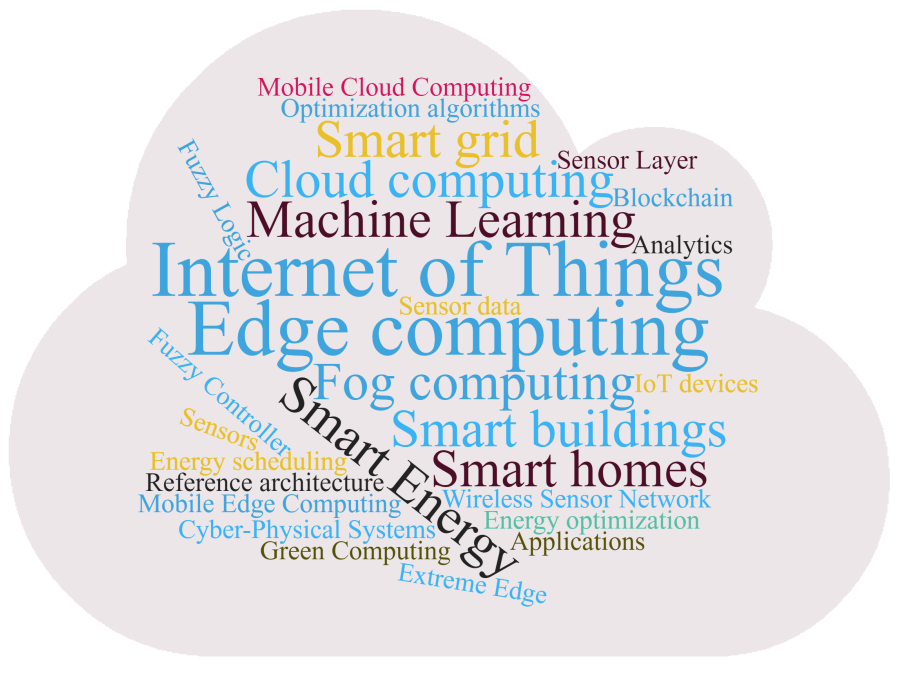

Figure 5. Keyword cloud from the Reviews Papers.

\subsection{RQ1: What Asset Types Have Been Reported about Edge Computing in Smart Energy Scenarios?}

The authors' will answer this question in order to identify relevant studies in which some type of asset is presented, such as review, architecture, framework, method, or model applied to Edge Computing in Smart Energy scenarios.

\section{- $\quad$ Frameworks}

Zhou et al. [60] presented a framework based on blockchain and Edge Computing. The authors developed a consortium blockchain-based secure energy trading mechanism for vehicle to grid (V2G). The authors validate their proposal through a simulation of an equilibrium analysis.

Alsmirat et al. [61] proposed a framework that integrates Cloud and Mobile Edge Computing (MEC), for data collection and bandwidth consumption management. This framework is designed to manage a system of video capture and transmission cameras. An MEC server controls the flow and temporary storage of the videos that will be sent to be stored definitively in a central cloud. However, the authors do not include a case study to validate the framework. The presented results are based on a simulated scenario.

Liu et al. [62] focused on designing an IoT-based energy management system using an Edge Computing infrastructure with deep reinforcement learning. The framework and software model of an IoT-based Edge Computing system have been proposed. Moreover, the authors illustrated the effectiveness of the proposed scheme by comparing its performance to that of a data set called RELOAD which represents the delays and high energy consumption costs from 40 homes, HVAC systems, and appliances. The results section presents a comparative graph of the delays when they occurred with different energy consumption schemes. 
Xia et al. [63] employed a load shifting technique on an edge device. Solar energy is integrated into a household energy system as a cost-effective solution through an edge-based energy management framework, which enables low electricity cost and saves on infrastructure construction costs.

Liu and $\mathrm{Gu}[64]$ presented a framework with important concepts on integrating Distributed energy resources (DERs) in edge devices, according to the IEC 61850 standard. In this paper, the Edge Computing gateway works with various protocols and converts them to IEC 61850-8-2 standards. In this framework, the edge gateway is in charge of distributing the application services and placing them near the IoT devices located at the edge of the network. Another function of the edge gateway is the collection, transmission, processing, and storage of data through the management of communication protocols as well as machine learning and business intelligence techniques.

Wang et al. [65] addressed the long term energy consumption minimization problem of mobile edge networks via computation offloading among MECSs. The authors proposed an online framework based on the Lyapunov technique to solve the optimization problem without requiring future network information. The framework has been evaluated by simulating results.

Figure 6 shows a set of concepts that the papers have in common: Edge computing, energy management, IoT, Energy Consumption, and Blockchain. The authors of these articles have allowed us to identify the importance that the integration of Edge Computing and other technologies is acquiring and the need to strengthen the security of the IoT infrastructures deployed in energy ecosystems.

Of the frameworks found, only three are validated, but using simulation tools to represent: intelligent vehicles, managing a video system and intelligent homes. The aim of these approaches is to effectively manage the use of energy and reducing consumption. However, none of the cases has been validated in a real scenario that allows one to measure the results obtained and consider them as optimal solutions for different Smart Energy scenarios.

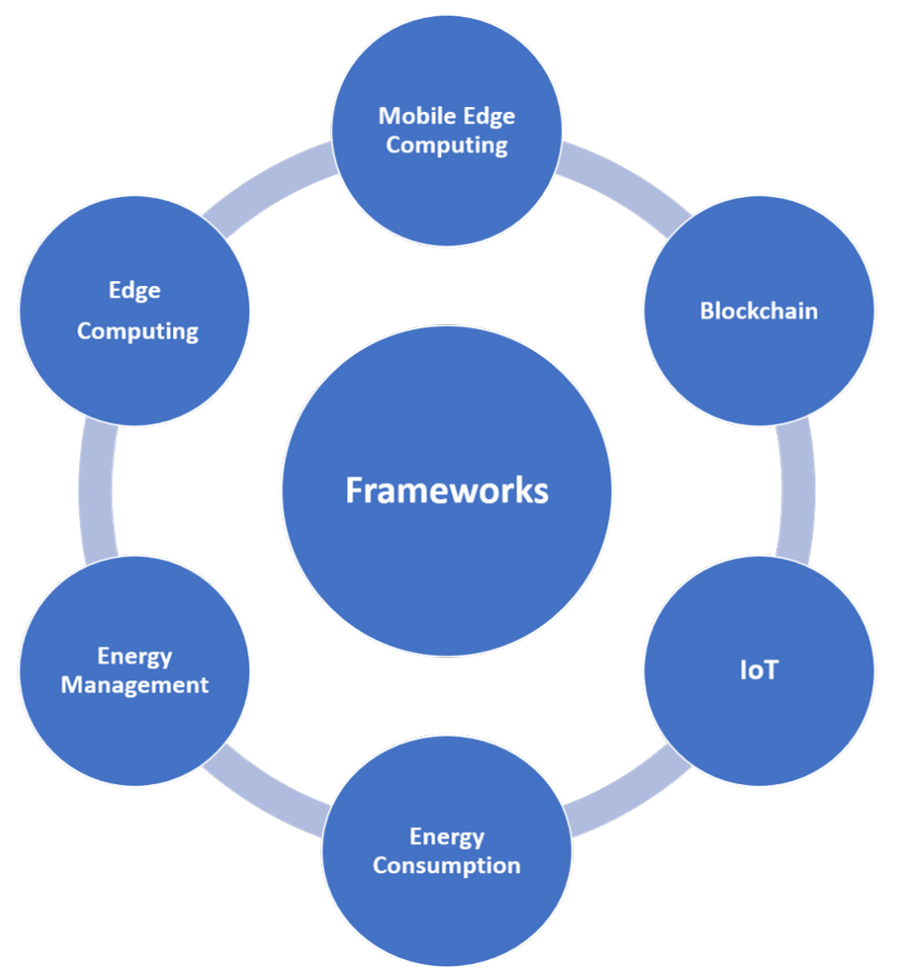

Figure 6. Common concepts in the analyzed frameworks.

\section{- Architectures}

In the context of relevant studies, some papers proposed architectures based on Edge Computing. These works are described as follows: 
Cicirelli et al. [66] proposed a three-layer architecture based on Edge Computing, for IoT scenarios, which they have called ITEMa. The authors defined a case study consisting of a smart office scenario in which they performed the methodological implementation of their architecture.

Suárez-Albela et al. [67] used a fog-edge architecture for the purpose of creating a testbed that would allow them to measure the security, power consumption, and communications when fog technologies were integrated into IoT devices. The authors proposed the evaluation of the architecture and the test bench generated according to energy consumption and data flow.

Ferrández-Pastor et al. [68] analyzed energy control, security, and air conditioning systems and services in an intelligent building. On the basis of this analysis, they proposed an Edge-Fog-Cloud architecture for IoT ecosystems in intelligent buildings. The architecture is deployed in a house, in which the electrical control panels act as the edge nodes that collect and send the data to the fog layer of the architecture.

Zhou et al. [69] reviewed the literature on the integration of Mobile Edge Computing with the internet of things and the challenges to reducing latency, energy, and resource consumption. Then, they propose an architecture that integrates both technologies. The validation of the proposed architecture is done through a vehicle traffic simulation using MATLAB and SUMO software.

$\mathrm{Li}$ and Zheng [70] mentioned concepts such as Edge Computing for the control of smart buildings. However, this is not the main focus of their solution because they propose a Cloud-based architecture. The Cloud is placed in the center of their design as the main component and is responsible for the management and control of all the deployed components and subsystems. Although the authors presented a diagram of the architecture, they do not detail how it is validated in a smart building environment. Finally, they made use of IAPview software to perform a simulation in which they generate a human-machine interface to control energy consumption in a smart building, however, the results of this simulation have not been presented.

Pacheco et al. [71] analyzed the disruption of Edge Computing and machine learning models as a consequence of the Internet of Things. Smart cities are an example of the large volume of data generated by IoT devices. In this way, the authors used an osmotic architecture with the aim of recognizing people by applying a deep learning model. The architecture integrates cloud, fog and mobile devices for Edge Computing to reduce latency and obtain answers in real-time. However, in the opinion of the authors of this research, they found limitations in fog computing that they are plan to address in future works.

Chen et al. [72] developed a cloud-fog-Edge Computing architecture that incorporates the convex optimized online learning (OCO) approach to address the heterogeneity of the tasks of existing IoT applications.

Liu et al. [73] proposed an architecture for IoT that integrates Edge Computing at the edge of the network and uses an Edge server that communicates with the Cloud. The novelty of this architecture is the incorporation of optimization models for energy consumption based on tensors. The authors presented a case study to evaluate the performance of their architecture over the traditional centralized scheme in the Cloud, that had previously been adapted in IoT scenarios. The results obtained from its implementation show the advantages of Edge Computing in the Internet of Things applications.

Sun and Ansari [74] described some of the problems of current IoT architectures, highlighting the scalability and real-time responsiveness for the processing of the large volume of data generated by IoT devices. As a solution, they developed an architecture with Edge-Fog Computing and Software Defined Networks (SDN). The objective of the authors has been to increase the capacity of IoT devices using Edge nodes and in this way reduce latency and bandwidth costs by reducing the traffic of data sent to the cloud. An intermediate fog-computing layer is in charge of controlling the information resources.

Long et al. [75] analyzed the problem of the computing of the resources of mobile users by simulating the deployment of an Edge-cloud computing architecture. The architecture is intended to accelerate the processing and development of the tasks of mobile users through an Edge server. 
The authors integrated a greedy algorithm in the Edge server to reduce the energy consumption of edge devices and optimize their performance.

Amadeo et al. [76] developed an architecture based on fog-cloud computing for a Smart Energy scenario. The authors validated the architecture by deploying it in a smart home and its lighting system based on the detection of movement or people. The authors indicated that state-of-the-art research recommends the use of Edge Computing technology over Fog Computing in IoT scenarios, however, this paper used the term fog computing despite the fact that the proposed architecture addresses a greater number of Edge Computing features, such as edge devices and a server in an intermediate layer that regulates data traffic through a remote cloud server.

Li et al. [77] identified cybersecurity as one of the problems of IoT-based energy management and distribution systems. The architecture proposed by the authors attempted to incorporate blockchain technology in the communication process between IoT devices and microgrid nodes in an energy distribution network.

Sittón-Candanedo et al. [6] presented a proposal for a tiered architecture with a modular approach that allowed for the management of complex solutions not only for Industry 4.0 environments but also for other scenarios such as smart cities, Smart Energy, healthcare, or precision agro-technology. The main contributions of the proposed architecture are the security and privacy offered by blockchain technologies.

The architectures listed in Table 3 use Edge Computing with the Internet of Things for Smart Energy environments. Their priority is to collect and analyze data from IoT devices, ensuring the connectivity and communication between their layers. Some of their limitations include:

- Scalability: they are designed for specific scenarios and have limited capacity to adapt to an increased number of users, hardware, and software;

- Security: These studies do not define clear strategies to guarantee data security in the proposed architectures;

- Standards: they do not use a reference standard such as ISO/IEC/IEEE 42020:2011, to design the architectures, thus the subsystems/components and the relationships between them are not clearly defined.

Other studies worth mentioning, are those presented by Amadeo et al. [76] and Li et al. [77] which included algorithms and encryption packets for data security in an intermediate layer of the architecture. The paper presented by Sittón-Candanedo et al. [6] described an architecture that includes Blockchain and data encryption in its three levels, however, the proposal would have been stronger if the authors had implemented Crypto-IoT boards in IoT devices, thus improving the system in terms of security, traceability, and data integrity.

Table 3. Comparison of the main characteristics of the architectures. The check-mark $(\checkmark)$ means advantages and $\mathrm{x}$-mark $(\boldsymbol{x})$ means weaknesses.

\begin{tabular}{|c|c|c|c|c|c|}
\hline Architectures & $\begin{array}{l}\text { Data Collection, } \\
\text { Analysis and } \\
\text { Performance }\end{array}$ & Scalability & $\begin{array}{l}\text { Security Solutions: } \\
\text { Data Encryption or } \\
\text { Blockchain }\end{array}$ & $\begin{array}{l}\text { Connectivity and } \\
\text { Communication }\end{array}$ & Standards \\
\hline Cicirelli et al. [66] & $\checkmark$ & $x$ & $x$ & $\checkmark$ & $x$ \\
\hline Suárez-Albela et al. [67] & $\checkmark$ & $x$ & $\checkmark$ & $\checkmark$ & $x$ \\
\hline Ferrández-Pastor et al. [68] & $\checkmark$ & $\checkmark$ & $x$ & $\checkmark$ & $x$ \\
\hline Zhou et al. [69] & $\checkmark$ & $x$ & $x$ & $\checkmark$ & $x$ \\
\hline $\mathrm{Li}$ and Zheng [70] & $\checkmark$ & $x$ & $x$ & $\checkmark$ & $x$ \\
\hline Pacheco et al. [71] & $\checkmark$ & $x$ & $x$ & $\checkmark$ & $x$ \\
\hline Chen et al. [72] & $\checkmark$ & $\checkmark$ & $x$ & $\checkmark$ & $x$ \\
\hline Liu et al. [73] & $\checkmark$ & $x$ & $x$ & $\checkmark$ & $x$ \\
\hline Sun and Ansari [74] & $\checkmark$ & $x$ & $x$ & $\checkmark$ & $x$ \\
\hline Long et al. [75] & $\checkmark$ & $x$ & $x$ & $\checkmark$ & $x$ \\
\hline Amadeo et al. [76] & $\checkmark$ & $x$ & $\checkmark$ & $\checkmark$ & $x$ \\
\hline Li et al. [77] & $\checkmark$ & $x$ & $\checkmark$ & $\checkmark$ & $x$ \\
\hline Sittón-Candanedo et al. [6] & $\checkmark$ & $\checkmark$ & $\checkmark$ & $\checkmark$ & $\checkmark$ \\
\hline
\end{tabular}




\section{- Models-Algorithms}

Petri et al. [78] studied the problem of collecting data in heterogeneous sensor networks and of high energy consumption/costs caused by IoT infrastructures in industrial processes. The authors simulated a model based on Edge Computing for the optimization of energy consumption and the consequent reduction in energy costs in industrial processes. The case of use defined for the simulation is the fishing industry.

Galanis et al. [79] analyzed the components of intelligent energy systems and how the Internet of Things paradigm affects the flow of data between smart grid devices. The model proposed by the authors is based on Edge Computing and is evaluated in a smart grid through its video surveillance system. The model aims to achieve smart grid scalability by allowing for the addition or removal of IoT devices that generate additional visual content for the devices in the network.

Chang and Lai [80] used neural network algorithms in Edge Computing devices for the management of resources and communication of IoT devices in a public lighting network. The authors used Edge Computing to reduce data traffic in the network, make predictions, distribute tasks, and allocate network resources. Communication took place via IoT devices deployed in every node of the street lighting network.

Zhao et al. [81] presented a model based on Deep learning in Mobile Edge Computing for the real-time prediction and management of data traffic, reduced latency, and energy consumption in the communication systems they use for example intelligent vehicles or devices used for virtual reality.

Fang et al. [82] considered energy consumption as one of the main problems of current mobile devices. As an alternative, the authors proposed the Lyapunov optimization technique with the OKRA control algorithm. In their opinion, the algorithm has achieved a balance between energy consumption, latency, and bandwidth resource allocation.

Gu et al. [83] developed an MTS (relaxation-based) algorithm which gives an optimal solution to the problem of resource distribution in edge devices and their energy consumption. The authors have shown that the proposed algorithm can efficiently reduce energy consumption through simulations, however, they have not specified what tools have been used to perform those simulations.

El Ghmary et al. [84] analyzed the energy consumption problem of a smart mobile device (SMD) during the execution of processes and tasks. As a solution, they presented a random algorithm developed in $\mathrm{C}++$ and simulated an Edge Computing environment. The algorithm has been validated by comparing the result with those obtained by other authors.

Li et al. [85] presented the concept of wireless mobile Edge Computing (WP-MEC) as a solution for energy transmission in an Internet of Things (IoT) scenario. By implementing an OCRM algorithm for maximizing online calculation speed, the authors aimed to control the allocation of resources such as bandwidth to each wireless device. The results are given in the form of a numerical simulation.

Wang et al. [86] proposed an algorithm based on the Lagrange method to the problem of energy consumption in mobile Edge Computing systems where users run a large volume of computing processes. The results and validation of the algorithm are presented numerically and the authors do not detail the tools used for the simulation.

Zhao et al. [87] used a Mobile Edge Computing architecture to deploy a selective download algorithm called ABSO so that mobile devices located at the edge of the network reduced energy consumption. This solution did not lead to increased latency. The authors compared the results of ABSO with other similar algorithms, through a simulation process but did not mention the tools used for the process.

Samie et al. [54] reviewed Edge Computing architectures and solutions for smart grid scenarios that integrate sensors, actuators, or devices from the Internet of Things. After analyzing the different alternatives, the authors proposed a regression and classification model that they evaluated through the implementation of the algorithm in a Raspberry Pi 3, model B installed in a smart home for the administration of household appliances and established limits for energy consumption. 
Pacheco et al. [71] proposed a deep learning model that has been deployed in a cloud-fog-Edge Computing architecture, for the purpose of controlling infrastructures and IoT devices to obtain energy savings in smart environments. To validate the algorithm a prototype of an intelligent classroom has been used, implemented internet of things technology for person recognition. The results obtained by the authors have demonstrated that it is possible to execute deep learning algorithms in an Edge Computing layer and that it is a suitable combination in cases where heterogeneous IoT devices generate data simultaneously.

According to Liu et al. [88], current solutions do not differentiate between cloud and Edge Computing when it comes to unmanned aerial vehicles (UAVs), which is why energy consumption, optimization, and task execution issues have not been fully addressed. The authors used Markov's approximation technique to propose a polynomial approximation algorithm to obtain a solution. To validate their proposal, they used a structure with wireless Edge Computing servers to communicate with the UAVs.

$\mathrm{Ku}$ et al. [89] analyzed the problem of energy consumption, latency and communication in road stations for electric- and solar-powered vehicles. Normally, there is a mismatch between the energy that is generated and that which is consumed due to the variability of the hours of sunshine. Thus, to optimize energy use, the article presented three algorithms that not only help control vehicle load but also manage resources and decrease latency. The authors validated their algorithm by simulating a scenario with vehicle traffic data, it demonstrated that energy consumption had been reduced and the charging service had been optimized.

Liu et al. [73] proposed a global optimization model applied to Edge Computing (EC), which is based on built tensors that include energy consumption, execution time, system reliability and quality of user experience (QoE). The authors aimed to integrate EC and cloud computing (CC) to obtain smart applications.

To Jararweh et al. [90], the optimization of energy consumption is one of the main problems of current smart scenarios, especially of those that are centralized in a cloud computing system. In this article, the authors addressed the problem by developing a mixed full line programming model (MILP) applied to an Edge Computing infrastructure with the purpose of optimizing energy consumption while reducing delays in the execution of computing processes and tasks.

Casadei et al. [91] developed a simulation of a use case where simultaneous urban events are described, with the aim of validating a model that integrates Edge Computing and the Internet of Things. The authors compared a centralized model in the cloud.

Li et al. [92] suggested a model for the analysis of energy consumption from the edge to the cloud on the Internet of Things platforms. The analyzed scenario is the data traffic generated by cameras integrated into intelligent vehicles. To validate the model, the authors used data sets and simulators in which the model was executed.

Ismail et al. [93] pointed to reducing energy consumption in mobile devices as the major challenge to adapting to the demands of 5G. Therefore, the authors present a queues management model for Edge Computing. It has been called AGCM to enable real-time services with lower energy consumption. To validate it, they used the NS2 simulator from Green Cloud Simulator.

Yang et al. [94] developed a model for energy management in Edge Computing systems, considering the execution of tasks and communication processes. To get the optimization they proposed an artificial fish swarm algorithm that can also achieve global convergence in a 5G Mobile Edge Computing (MEC). Simulation results demonstrate the efficiency and effectiveness of the proposed algorithm.

Figure 7 represents the main algorithms used or proposed in the analyzed articles. Optimization, deep learning and neural network-based algorithms represent the largest percentage of the solutions proposed to energy problems.

In a more detailed analysis, we have identified that the articles particularly address four problems: consumption, efficiency, management, and optimization. In this regard, we have categorized the 
algorithms used in each problem. Figure 8 presents the most commonly used algorithms as a solution to each problem.

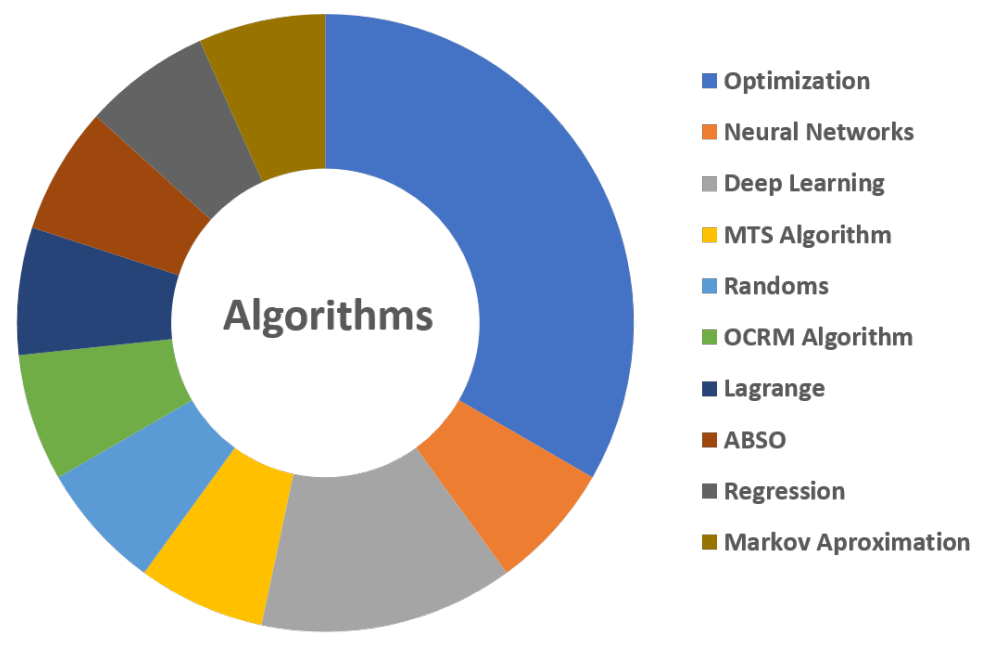

Figure 7. Main algorithms used in the analyzed papers.

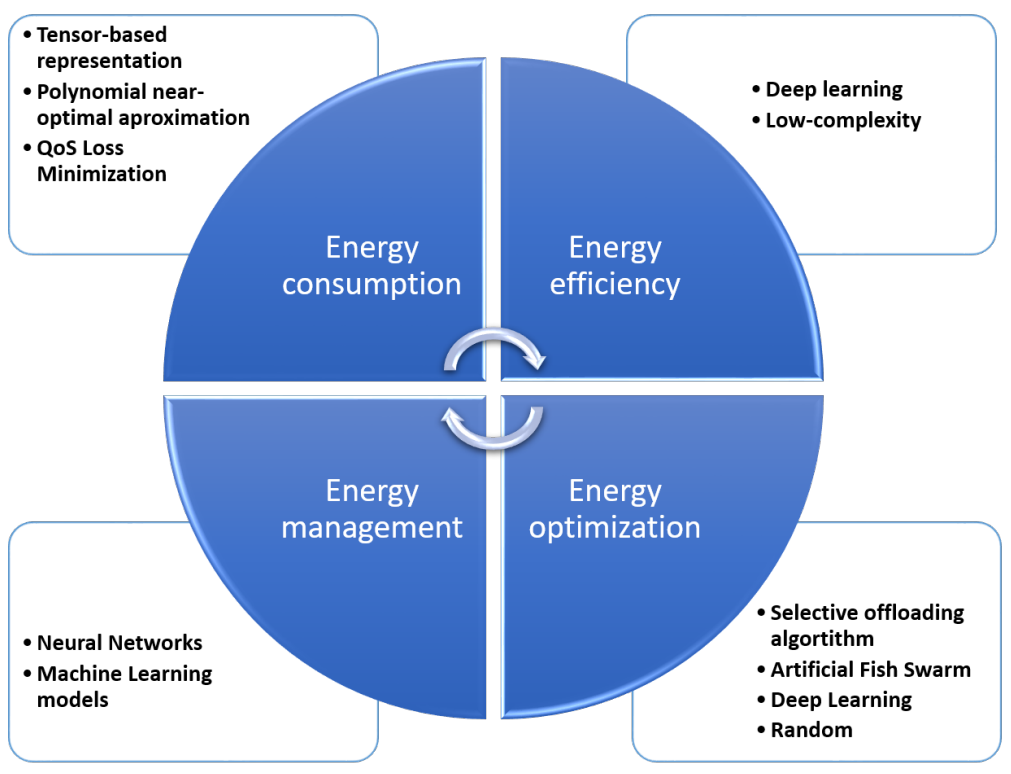

Figure 8. Algorithms for the identified energy issues.

\section{- Platforms}

Briante et al. [95] performed a review of iSapiens, an agent-based platform intended for smart urban environments or ecosystems. The authors presented case studies and applications related to Smart Cities and Smart Grids, in which the platform is used, demonstrating its effectiveness for the development of applications in these scenarios. This platform addresses data management and processing by coupling the cloud computing paradigm with Edge Computing, and providing high-power computing systems, exploitable for high-demand tasks, and distributed processing capabilities that support reactive and location-dependent processing.

\section{- Methods}

According to Xu et al. [96], the set of applications in a Smart City leads to high energy consumption, especially in the mobile devices that interact with them. The authors propose a method called EACO 
for the reduction of energy consumption in these devices during the execution of the processes. The method integrates a genetic algorithm of non-dominant classification (NSGA-II) that allows to optimize and reduce energy consumption in Edge nodes. This makes it possible to deploy a Smart Edge Computing platform. The research results are presented through simulation comparing previously proposed methods with EACO.

The papers analyzed in this systematic mapping study have been categorized by the solutions they bring to Smart Energy scenarios. However, the Smart Energy context is complex and requires developments and proposals that will reduce energy consumption and cost, improve operational efficiency through infrastructure management, make decisions based on data analysis and real-time access to information. In this regard, the results of research question 1 have allowed us to identify a limited number of research papers, that proposes the design and implementation of unified frameworks and platforms, which integrate Edge Computing and IoT for a Smart Energy environment.

With Edge Computing, all the information produced by IoT devices is processed to the maximum, thus freeing up the computational load of centralized servers, avoiding the overload of network traffic and reducing the response time required by the new Internet applications of Things. Therefore, the integration of EC-IoT for Smart Energy environments allows: reducing the computing overload of portable devices; this helps to save energy consumption; the design of distributed and decentralized architectures to efficiently use the available resources of the network and the cloud [97].

As the complexity of Smart Energy scenarios increases, EC-loT solutions can offer services using different logical distributions to achieve the desired goal. Actual execution will depend on the use case and the platforms should be dynamic enough to adapt accordingly to these changing requirements.

\subsection{RQ2: How Do Smart Energy Scenarios Benefit from Edge Computing?}

Solutions that use Edge Computing to optimize the capabilities of IoT devices represent a growing field of research in both business and academic environments. Thanks to systematic mapping, the need for new reference architectures has been identified, capable of supporting the process of development of Smart Energy scenarios.

To respond to today's market demands, energy solutions must give users the opportunity to program their energy consumption in a smart and personalized manner [83]. Important aspects to be taken into account in this type of developments are Edge Computing and the existence of variants in energy generation indexes and data processing demands. In Smart Energy scenarios, there must be an adequate distribution of tasks and efficient programming of energy requirements so that there is a correspondence between supply and demand factors.

Ferrández-Pastor et al. [68] proposed an architecture based on embedded devices and Edge Computing for intelligent infrastructures. The authors validated their architecture in a residential building where they monitored energy use. Edge nodes are responsible for controlling renewable energy subsystems and appliances. The edge layer allowed for the integration of operational processes with energy management and security controls. This has made it easier to design intelligent services with these architectures.

Xia et al. [63] presented an architecture for energy consumption management based on Edge Computing. The architecture is validated in a prototype system with a Raspberry Pi and intelligent appliances. The edges nodes manage load changes, creating an energy management system that manages the use of solar energy. The authors obtained results that demonstrate a significant reduction in energy consumption costs which have been obtained without altering the functionality of the equipment and therefore user comfort.

Liu et al. [73] proposed a three-layer architecture for IoT with the aim of optimizing the advantages offered by the edge and the cloud. In their proposal, the authors included an optimization model for IoT devices which reduces energy consumption, fastens execution times and increases system reliability. To carry out the calculations, the authors used tensors that regulated the relationship of the assignment with the heterogeneity of the devices. 
Amadeo et al. [76] Presented a reference architecture for a Smart Energy scenario, in this case, a home, where automation, control, supervision, and optimization were required. The architecture's main component is an IoT platform that includes Edge Computing and all its general capabilities.

\section{Conclusions}

Thanks to current technological development, in the near future it will be possible to have infrastructures and innovative software solutions aimed at homes and office complexes. There will be a large quantity of small, high-performance sensors, actuators, and controllers, contributing to the high-quality management in the existing physical structures. Users will be able to perform intelligent management and automated monitoring of areas and services such as lighting, energy consumption, surveillance, and healthcare. Currently, the implementation of technological solutions based on EC and IoT operating environments has facilitated the development of intelligent services and applications. For example, smart city, smart home, and smart healthcare. However, to correctly apply these technologies in different scenarios, it will be necessary to comply with the different requirements and operational characteristics. The implementation of this type of technological ecosystem will allow one to reach diverse objectives, among which are greater energy efficiency, increased reliability, timely execution of the tasks and processes, and higher quality of life of the citizens. The role of Edge Computing, which will be implemented in existing structures, will be to facilitate the interconnection of devices and the home network with the Internet. This will contribute significantly to improving the efficiency and effectiveness of the general tasks and processes. Moreover, energy consumption will be reduced significantly. To achieve high levels of productivity when implementing infrastructures and architectures based on EC it is necessary to overcome problems caused by the diversity of IoT devices, complex communication network systems, and different energy consumption rates.

Author Contributions: Conceptualization, I.S.-C., R.S.A., and Ó.G.; investigation, I.S.-C., R.S.A., and Ó.G.; methodology, A.G. and S.R.-G.; writing—original draft, I.S.-C., R.S.A., and Ó.G.; writing—review and editing, A.G. and S.R.-G. All authors have read and agreed to the published version of the manuscript.

Funding: This research has been supported by the project "Intelligent and sustainable mobility supported by multi-agent systems and Edge Computing (InEDGEMobility): Towards Sustainable Intelligent Mobility: Blockchain-based framework for IoT Security", Reference: RTI2018-095390-B-C32, financed by the Spanish Ministry of Science, Innovation and Universities (MCIU), the State Research Agency (AEI) and the European Regional Development Fund (FEDER). Inés Sittón-Candanedo has been supported by the IFARHU—SENACYT scholarship program (Government of Panamá).

Acknowledgments: Thanks are due to researchers who supported us during the mapping process to better classify the primary studies: Ricardo Silveira (ricardo.silveira@ufsc.br) Federal University of Santa Catarina, Brazil; Luis Fernando Castillo Ossa (luis.castillo@ucaldas.edu.co) from University of Caldas, Colombia and Cristian Iván Pinzón Trejos (c.pinzon.t@gmail.com) from Technological University of Panama.

Conflicts of Interest: The authors declare no conflict of interest.

\section{Abbreviations}

The following abbreviations are used in this manuscript:

SMS Systematic Mapping Study

EC Edge Computing

WS1 Web of Science Search String 1

WS2 Web of Science Search String 2

WS3 Web of Science Search String 3

SC1 Scopus Search String 1

SC2 Scopus Search String 2

SC3 Scopus Search String 3

SP1 Springer Search String 1

SP2 Springer Search String 2

SP3 Springer Search String 3 


\section{Appendix A}

Table A1. Included papers.

\begin{tabular}{|c|c|c|c|c|c|c|}
\hline Author & Title & Year & Publication Type & Research Type & Evolution Activity & Asset Type \\
\hline Sittón-Candanedo et al. [6] & $\begin{array}{l}\text { A review of Edge Computing reference } \\
\text { architectures and a new global edge proposal. }\end{array}$ & 2019 & Journal & Conceptual, Experience, Validation. & Implement & Architecture \\
\hline Xu et al. [96] & $\begin{array}{l}\text { An energy-aware computation offloading method } \\
\text { for smart Edge Computing in wireless } \\
\text { metropolitan area networks. }\end{array}$ & 2019 & Journal & Conceptual, Experience, Validation & Implement & Method \\
\hline Liu and Gu [64] & $\begin{array}{l}\text { Modeling and integrating PV stations into IEC } \\
61850 \text { XMPP intelligent Edge Computing gateway. }\end{array}$ & 2019 & Journal & Conceptual and Experience & Implement & Architecture \\
\hline Cicirelli et al. [66] & $\begin{array}{l}\text { ITEMa: A methodological approach for cognitive } \\
\text { Edge Computing IoT ecosystems. }\end{array}$ & 2019 & Journal & Conceptual and Experience & Implement & Architecture \\
\hline Petri et al. [78] & Ensemble-based network edge processing. & 2019 & Conference paper & Conceptual & Analyze & Model \\
\hline Shah et al. [48] & $\begin{array}{l}\text { A review on energy consumption optimization } \\
\text { techniques in IoT based smart } \\
\text { building environments. }\end{array}$ & 2019 & Journal & Conceptual & Analyze & NA \\
\hline Galanis et al. [79] & $\begin{array}{l}\text { Edge Computing and efficient resource } \\
\text { management for integration of video devices in } \\
\text { smart grid deployments. }\end{array}$ & 2019 & Book Chapter & Conceptual, Experience & Implement & Model \\
\hline Fei et al. [49] & $\begin{array}{l}\text { CPS data streams analytics based on machine } \\
\text { learning for Cloud and Fog Computing: A survey. }\end{array}$ & 2019 & Journal & Conceptual & Analyze & NA \\
\hline Briante et al. [95] & $\begin{array}{l}\text { A social and pervasive IoT platform for } \\
\text { developing smart environments }\end{array}$ & 2019 & Book Chapter & Conceptual, Experience & Implement & Platform \\
\hline Zhou et al. [60] & $\begin{array}{l}\text { Blockchain and Edge Computing Based } \\
\text { Vehicle-to-Grid Energy Trading in Energy Internet. }\end{array}$ & 2018 & Conference paper & Conceptual, Experience & Analyze & Framework \\
\hline Suárez-Albela et al. [67] & $\begin{array}{l}\text { A practical evaluation on RSA and ECC-based } \\
\text { cipher suites for iot high-security energy-efficient } \\
\text { fog and mist computing devices. }\end{array}$ & 2018 & Journal & Experience & & \\
\hline Ferrández-Pastor et al. [68] & $\begin{array}{l}\text { Deployment of IoT edge and fog computing } \\
\text { technologies to develop smart building services }\end{array}$ & 2018 & Journal & Conceptual, Experience, Validation. & Implement & Architecture \\
\hline Ding and Janssen [98] & $\begin{array}{l}\text { Opportunities for applications using } 5 \mathrm{G} \text { networks: } \\
\text { Requirements, challenges and outlook. }\end{array}$ & 2018 & Conference Paper & Conceptual & Analyze & NA \\
\hline Leligou et al. [99] & $\begin{array}{l}\text { Smart Grid: A demanding use case for } \\
\text { 5G technologies }\end{array}$ & 2018 & Conference Paper & Conceptual & Analyze & NA \\
\hline Zhou et al. [69] & $\begin{array}{l}\text { An air-ground integration approach for mobile } \\
\text { Edge Computing in IoT }\end{array}$ & 2018 & Journal & Conceptual, Experience, Validation. & Implement & Architecture \\
\hline Li and Zheng [70] & $\begin{array}{l}\text { Application of universal control platform in } \\
\text { intelligent building }\end{array}$ & 2018 & Conference Paper & Conceptual & Analyze & Architecture \\
\hline Rajith et al. [100] & $\begin{array}{l}\text { Real-time optimized HVAC control system on top } \\
\text { of an IoT framework }\end{array}$ & 2018 & $\begin{array}{l}\text { Conceptual, } \\
\text { Experience, } \\
\text { Validation. }\end{array}$ & Implement & Framework & \\
\hline
\end{tabular}


Table A1. Cont.

\begin{tabular}{|c|c|c|c|c|c|c|}
\hline Author & Title & Year & Publication Type & Research Type & Evolution Activity & Asset Type \\
\hline Lujic et al. [101] & $\begin{array}{l}\text { Adaptative Recovery of Incomplete Datasets for } \\
\text { Edge Analytics }\end{array}$ & 2018 & Conferences paper & Conceptual, Experience, Validation. & Implement & $\begin{array}{l}\text { Architecture, } \\
\text { Model }\end{array}$ \\
\hline Liu et al. [102] & $\begin{array}{l}\text { Blockchain-Enabled security in electric vehicles } \\
\text { cloud and Edge Computing }\end{array}$ & 2018 & Journal & Conceptual & Analyze & Architecture \\
\hline Hou et al. [103] & $\begin{array}{l}\text { Green survivable collaborative Edge Computing in } \\
\text { Smart Cities }\end{array}$ & 2018 & Journal & Conceptual & Analyze & NA \\
\hline Kiss et al. [104] & Deployment of IoT applications on 5G edge & 2018 & Conference paper & Conceptual & Analyze & NA \\
\hline Pan and Yang [105] & $\begin{array}{l}\text { Cibersecurity challenges and opportunities in the } \\
\text { new "Edge Computing + iot" world }\end{array}$ & 2018 & Conference paper & Conceptual & Analyze & NA \\
\hline Shukla et al. [106] & $\begin{array}{l}\text { Software-defined network and cloud-edge } \\
\text { collaboration for smart and connected vehicles }\end{array}$ & 2018 & Conference paper & Conceptual & Analyze & NA \\
\hline Rajaei and Mirzaei [107] & IoT, smart homes and ZigBee simulation & 2018 & Conference paper & Conceptual, E & Analyze & NA \\
\hline Chang and Lai [80] & $\begin{array}{l}\text { Campus Edge Computing Network Based on IoT } \\
\text { Street Lighting Nodes }\end{array}$ & 2018 & Journal (in-press) & Conceptual, Experience, Validation & Implement & Model \\
\hline Alsmirat et al. [61] & $\begin{array}{l}\text { Internet of surveillance: a cloud supported } \\
\text { large-scale wireless surveillance system }\end{array}$ & 2017 & Journal & Conceptual, Experience, Validation & Implement & Framework \\
\hline Muñoz et al. [108] & $\begin{array}{l}\text { The CTTC 5G End to End Experimental platform: } \\
\text { Integrating Heterogeneous Wireless/Optical } \\
\text { Networks, Distributed Cloud and IoT Devices }\end{array}$ & 2016 & Journal & Conceptual, Experience, Validation & Implement & Platform \\
\hline Zhao et al. [81] & $\begin{array}{l}\text { Deep Learning based mobile data offloading in } \\
\text { mobile Edge Computing systems }\end{array}$ & 2019 & Journal & Conceptual, Experience & Analyze & Model \\
\hline Fang et al. [82] & $\begin{array}{l}\text { OKRA: optimal task and resource allocation for } \\
\text { energy minimisation in mobile Edge } \\
\text { Computing systems }\end{array}$ & 2019 & Journal & Conceptual, Experience & Analyze & Model \\
\hline Gu et al. [83] & $\begin{array}{l}\text { Energy efficient task allocation and energy } \\
\text { scheduling in green energy powered } \\
\text { Edge Computing }\end{array}$ & 2019 & Journal & Conceptual, Experience & Analyze & Model \\
\hline El Ghmary et al. [84] & $\begin{array}{l}\text { Energy and computational resources optimisation } \\
\text { in a mobile Edge Computing node }\end{array}$ & 2019 & Conference paper & Conceptual & Analyze & Model \\
\hline Portilla et al. [50] & $\begin{array}{l}\text { The extreme edge at the bottom of the Internet of } \\
\text { Things: A review }\end{array}$ & 2019 & Journal & Conceptual & Analyze & NA \\
\hline Hua et al. [109] & $\begin{array}{l}\text { Energy optimisation for Cellular-Connected UAV } \\
\text { Mobile Edge Computing Systems }\end{array}$ & 2019 & Conference paper & Conceptual & Analyze & Model \\
\hline Li et al. [85] & $\begin{array}{l}\text { Dynamic multi-user computation offloading for } \\
\text { wireless powered mobile Edge Computing }\end{array}$ & 2019 & Journal & Conceptual, Experience & Analyze & Model \\
\hline Chen et al. [72] & $\begin{array}{l}\text { Learning and management for Internet of Things: } \\
\text { Accounting for Adaptivity and Scalabilkity. }\end{array}$ & 2019 & Journal & Conceptual & Analyze & Architecture \\
\hline Liu et al. [62] & $\begin{array}{l}\text { Intelligent Edge Computing for IoT-Based Energy } \\
\text { Management in Smart Cities }\end{array}$ & 2019 & Journal & Conceptual, Experience, Validation & Implement & $\begin{array}{l}\text { Framework, } \\
\text { Model. }\end{array}$ \\
\hline Wang et al. [86] & $\begin{array}{l}\text { Multi-antenna NOMA for computation offloading } \\
\text { in multi-user mobile Edge Computing systems }\end{array}$ & 2019 & Journal & Conceptual, Experience & Analyze & Model \\
\hline
\end{tabular}


Table A1. Cont.

\begin{tabular}{|c|c|c|c|c|c|c|}
\hline Author & Title & Year & Publication Type & Research Type & Evolution Activity & Asset Type \\
\hline Alsuhli and Khattab [110] & A Fog-based IoT Platform for Smart Buildings & 2019 & Conference Paper & Conceptual & Analyze & NA \\
\hline Wu et al. [111] & $\begin{array}{l}\text { Wireless Powered User Cooperative Computation } \\
\text { in Mobile Edge Computing Systems }\end{array}$ & 2019 & Conference Paper & Conceptual & Analyze & NA \\
\hline Huang et al. [112] & $\begin{array}{l}\text { Green virtualized Edge Computing: Successive } \\
\text { Count model analysis }\end{array}$ & 2019 & Conference paper & Conceptual & Analyze & NA \\
\hline Zhao et al. [87] & $\begin{array}{l}\text { Selective offloading by exploiting ARIMA-BP for } \\
\text { energy optimisation in mobile Edge } \\
\text { Computing networks }\end{array}$ & 2019 & Journal & Conceptual, Experience & Analyze & Model \\
\hline Samie et al. [54] & $\begin{array}{l}\text { Edge Computing for smart grid: an overview on } \\
\text { architectures an solutions }\end{array}$ & 2019 & Book chapter & Conceptual, experience & Implement & Model \\
\hline Gilbert et al. [51] & $\begin{array}{l}\text { A critical review of edge and fog computing for } \\
\text { smart grid applications }\end{array}$ & 2019 & Conference paper & Conceptual & Analyze & NA \\
\hline Pacheco et al. [71] & $\begin{array}{l}\text { A smart classroom based on deep learning and } \\
\text { osmotic IoT Computing }\end{array}$ & 2018 & Conference Paper & Conceptual, experience, validation & Implement & $\begin{array}{l}\text { Architecture, } \\
\text { model }\end{array}$ \\
\hline Liu et al. [88] & $\begin{array}{l}\text { Joint computation offloading and routing } \\
\text { optimisation for UAV-Edge-cloud } \\
\text { computing environments }\end{array}$ & 2018 & Conference paper & Conceptual, experience & Analyze & Model \\
\hline Xia et al. [63] & Edge-based energy management for smart homes & 2018 & Conference paper & Conceptual, Experience, Validation & Implement & $\begin{array}{l}\text { Framework, } \\
\text { model }\end{array}$ \\
\hline Ku et al. [89] & $\begin{array}{l}\text { Quality of services optimisation for vehicular Edge } \\
\text { Computing with solar-powered read side units }\end{array}$ & 2018 & Conference paper & Conceptual, Experience & Analyze & Model \\
\hline Zhang et al. [113] & $\begin{array}{l}\text { Energy-efficient online resource management and } \\
\text { allocation optimisation in multi-user multi-task } \\
\text { mobile-Edge Computing system with hybrid } \\
\text { energy harvesting }\end{array}$ & 2018 & $\begin{array}{l}\text { Conceptual, } \\
\text { Experience }\end{array}$ & Analyze & Model & \\
\hline Zhou et al. [114] & $\begin{array}{l}\text { Computation rate maximisation in UAV-Enabled } \\
\text { wireless-powered mobile-Edge } \\
\text { Computing systems }\end{array}$ & 2018 & Journal & Conceptual & Analyze & NA \\
\hline Cao et al. [115] & $\begin{array}{l}\text { Mobile Edge Computing for Cellular-Connected } \\
\text { UAV: Computation Offloading and } \\
\text { Trajectory Optimization }\end{array}$ & 2018 & Conference Paper & Conceptual & Analyze & NA \\
\hline Rimal et al. [116] & $\begin{array}{l}\text { Experimental test-bed for Edge Computing in } \\
\text { fiber-wireless broadband access networks }\end{array}$ & 2018 & Journal & Conceptual & Analyze & NA \\
\hline Li et al. [117] & $\begin{array}{l}\text { On enabling sustainable Edge Computing with } \\
\text { renewable energy resources }\end{array}$ & 2018 & Conference paper & Conceptual, experience & Analyze & NA \\
\hline Yang et al. [94] & $\begin{array}{l}\text { Mobile Edge Computing empowered energy } \\
\text { efficient task offloading in } 5 \mathrm{G}\end{array}$ & 2018 & Journal & Conceptual, experience & Analyze & $\begin{array}{l}\text { Architecture, } \\
\text { model }\end{array}$ \\
\hline Fan and Ansari [118] & $\begin{array}{l}\text { Application aware workload allocation for Edge } \\
\text { Computing based IoT }\end{array}$ & 2018 & Journal & Conceptual, Experience & Analyze & Model \\
\hline Ahmadoh and Lo'ai [119] & $\begin{array}{l}\text { Power consumption experimental analysis in } \\
\text { smart phones }\end{array}$ & 2018 & Conference paper & Conceptual & Analyze & NA \\
\hline
\end{tabular}


Table A1. Cont.

\begin{tabular}{|c|c|c|c|c|c|c|}
\hline Author & Title & Year & Publication Type & Research Type & Evolution activity & Asset type \\
\hline Alnoman et al. [120] & $\begin{array}{l}\text { Energy efficiency on fully cloudified mobile } \\
\text { networks: survey, challenges and open issues }\end{array}$ & 2018 & Journal & Conceptual & Analyze & NA \\
\hline Luo et al. [121] & $\begin{array}{l}\text { Energy efficient autonomic offloading in mobile } \\
\text { Edge Computing }\end{array}$ & 2018 & Conference paper & Conceptual & Analyze & NA \\
\hline Wang et al. [65] & $\begin{array}{l}\text { Cooperative Edge Computing with sleep control } \\
\text { under non-uniform traffic in mobile edge networks }\end{array}$ & 2018 & Journal & Conceptual & Analyze & NA \\
\hline Liu et al. [73] & $\begin{array}{l}\text { A tensor-based holistic Edge Computing } \\
\text { optimisation framework for Internet of Things }\end{array}$ & 2018 & Journal & Conceptual, experience, validation & Implement & $\begin{array}{l}\text { Architecture } \\
\text { model }\end{array}$ \\
\hline $\begin{array}{l}\text { Väänänen and Hämäläinen } \\
\text { [52] }\end{array}$ & $\begin{array}{l}\text { Requirements for Energy Efficient Edge } \\
\text { Computing: A survey. }\end{array}$ & 2018 & Conference paper & Conceptual & Analyze & NA \\
\hline Jararweh et al. [90] & $\begin{array}{l}\text { Delay-aware power optimisation model for mobile } \\
\text { Edge Computing systems }\end{array}$ & 2017 & Journal & Conceptual, Experience & Analyze & Model \\
\hline Mao et al. [53] & $\begin{array}{l}\text { A survey on mobile Edge Computing: } \\
\text { the communication perspective. }\end{array}$ & 2017 & Journal & Conceptual & Analyze & NA \\
\hline ur Rehman et al. [122] & $\begin{array}{l}\text { Towards next-generation heterogeneous mobile } \\
\text { data stream mining applications: opportunities, } \\
\text { challenges and future research directions }\end{array}$ & 2017 & Journal & Conceptual & Analyze & NA \\
\hline Sun and Ansari [74] & $\begin{array}{l}\text { EdgeIot: Mobile Edge Computing for the Internet } \\
\text { of Things }\end{array}$ & 2016 & Journal & Conceptual, experience & Analyze & Architecture \\
\hline Casadei et al. [91] & $\begin{array}{l}\text { A development approach for collective } \\
\text { opportunistic Edge-of-Things services }\end{array}$ & 2019 & Journal & Conceptual, Experience & Analyze & Model \\
\hline Li et al. [92] & $\begin{array}{l}\text { End to end energy models for Edge Cloud-based } \\
\text { IoT platforms: Application to data stream analysis } \\
\text { in IoT }\end{array}$ & 2018 & Journal & Conceptual Experience & Analyze & Model \\
\hline Long et al. [75] & $\begin{array}{l}\text { Energy-efficient offloading in mobile Edge } \\
\text { Computing with edge-cloud collaboration }\end{array}$ & 2018 & Book Chapter & Conceptual, Experience & Analyze & Architecture \\
\hline Ismail et al. [93] & $\begin{array}{l}\text { AGCM: Active Queue Management-Based Green } \\
\text { Cloud Model for Mobile Edge Computing }\end{array}$ & 2019 & Journal & Conceptual, experience & Analyze & Model \\
\hline Singh et al. [123] & $\begin{array}{l}\text { Fog computing: from architecture to Edge } \\
\text { Computing and big data processing }\end{array}$ & 2019 & Journal & Conceptual & Analyze & NA \\
\hline Zheng et al. [124] & $\begin{array}{l}\text { A feedback prediction model for resource usage } \\
\text { and offloading time in Edge Computing }\end{array}$ & 2018 & Book Chapter & Conceptual & Analyze & NA \\
\hline Mukhlif et al. [125] & $\begin{array}{l}\text { Green transmission for C-RAN based on SWIPT in } \\
\text { 5G: A review }\end{array}$ & 2019 & Journal & Conceptual & Analyze & NA \\
\hline Khattar et al. [126] & $\begin{array}{l}\text { Toward energy-efficient cloud computing: } \\
\text { a survey of dynamic power management and } \\
\text { heuristics-based optimisation techniques }\end{array}$ & 2019 & Journal & Conceptual & Analyze & NA \\
\hline Amadeo et al. [76] & $\begin{array}{l}\text { On the integration of information centric } \\
\text { networking and fog computing for smart } \\
\text { home services }\end{array}$ & $\begin{array}{l}\text { Book } \\
\text { Chapter }\end{array}$ & Conceptual & Analyze & Architecture & \\
\hline Khanna et al. [59] & $\begin{array}{l}\text { IoT Architecture for Preventive Energy } \\
\text { Conservation of Smart Buildings }\end{array}$ & 2019 & Book Chapter & Conceptual, experimental & Analyze & Architecture \\
\hline
\end{tabular}


Table A1. Cont.

\begin{tabular}{|c|c|c|c|c|c|c|}
\hline Author & Title & Year & Publication Type & Research Type & Evolution activity & Asset type \\
\hline Sittón-Candanedo et al. [16] & $\begin{array}{l}\text { Edge Computing, IoT and Social Computing in } \\
\text { Smart Energy Scenarios }\end{array}$ & 2019 & Journal & Conceptual, Experience, Validation & Implement & Architecture \\
\hline Huang et al. [112] & Fundamentals and literature review & 2019 & Book chapter & Conceptual & Analyze & NA \\
\hline Saravanan et al. [127] & $\begin{array}{l}\text { Smart Cities-IoT: Evolution of Applications, } \\
\text { Architectures, Technologies, Peesent Scenarios and } \\
\text { Future Dream }\end{array}$ & 2019 & Book chapter & Conceptual & Analyze & NA \\
\hline Li et al. [77] & $\begin{array}{l}\text { Cyber-Secure decentralized energy management } \\
\text { for IoT-enabled active distribution networks }\end{array}$ & 2018 & Journal & Conceptual, experimental & Analyze & Architecture \\
\hline Bermbach et al. [128] & A reserarch perspective on fog computing & 2018 & Book chapter & Conceptual & Analyze & NA \\
\hline Wlodarczak [55] & $\begin{array}{l}\text { Smart Cities enabling technologies for } \\
\text { Future Living }\end{array}$ & 2017 & Book chapter & Conceptual & Analyze & NA \\
\hline
\end{tabular}




\section{References}

1. Lund, H.; Andersen, A.N.; Østergaard, P.A.; Mathiesen, B.V.; Connolly, D. From electricity smart grids to smart energy systems-A market operation based approach and understanding. Energy 2012, 42, 96-102. [CrossRef]

2. Lund, H.; Østergaard, P.A.; Connolly, D.; Mathiesen, B.V. Smart energy and smart energy systems. Energy 2017, 137, 556-565. [CrossRef]

3. Kabalci, Y.; Kabalci, E.; Padmanaban, S.; Holm-Nielsen, J.B.; Blaabjerg, F. Internet of Things Applications as Energy Internet in Smart Grids and Smart Environments. Electronics 2019, 8, 972. [CrossRef]

4. Vinagre, E.; De Paz, J.F.; Pinto, T.; Vale, Z.; Corchado, J.M.; Garcia, O. Intelligent energy forecasting based on the correlation between solar radiation and consumption patterns. In Proceedings of the 2016 IEEE Symposium Series on Computational Intelligence (SSCI), Athens, Greece, 6-9 December 2016.

5. Al-Ali, A.R.; Zualkernan, I.A.; Rashid, M.; Gupta, R.; Alikarar, M. A smart home energy management system using IoT and big data analytics approach. IEEE Trans. Consum. Electron. 2017, 63, 426-434. [CrossRef]

6. Sittón-Candanedo, I.; Alonso, R.S.; Corchado, J.M.; Rodríguez-González, S.; Casado-Vara, R. A review of edge computing reference architectures and a new global edge proposal. Future Gener. Comput. Syst. 2019, 99, 278-294. [CrossRef]

7. Baronti, F.; Vazquez, S.; Chow, M.Y. Modeling, control, and integration of energy storage systems in e-transportation and smart grid. IEEE Trans. Ind. Electron. 2018, 65, 6548-6551. [CrossRef]

8. García, Ó.; Alonso, R.S.; Prieto, J.; Corchado, J.M. Energy Efficiency in Public Buildings through Context-Aware Social Computing. Sensors 2017, 17, 826. [CrossRef]

9. García, O.; Chamoso, P.; Prieto, J.; Rodríguez, S.; de la Prieta, F. A Serious Game to Reduce Consumption in Smart Buildings. In Highlights of Practical Applications of Cyber-Physical Multi-Agent Systems; Bajo, J., Vale, Z., Hallenborg, K., Rocha, A.P., Mathieu, P., Pawlewski, P., Del Val, E., Novais, P., Lopes, F., Duque Méndez, N.D., et al., Eds.; Springer International Publishing: Cham, Switzerland, 2017; pp. 481-493.

10. García, Ó.; Prieto, J.; Alonso, R.; Corchado, J. A framework to improve energy efficient behaviour at home through activity and context monitoring. Sensors 2017, 17, 1749. [CrossRef]

11. González-Briones, A.; Chamoso, P.; De La Prieta, F.; Demazeau, Y.; Corchado, J. Agreement technologies for energy optimization at home. Sensors 2018, 18, 1633. [CrossRef]

12. González-Briones, A.; Prieto, J.; De La Prieta, F.; Herrera-Viedma, E.; Corchado, J. Energy optimization using a case-based reasoning strategy. Sensors 2018, 18, 865. [CrossRef]

13. González-Briones, A.; De La Prieta, F.; Mohamad, M.; Omatu, S.; Corchado, J. Multi-agent systems applications in energy optimization problems: A state-of-the-art review. Energies 2018, 11, 1928. [CrossRef]

14. Wang, Y.; Chen, Q.; Gan, D.; Yang, J.; Kirschen, D.S.; Kang, C. Deep learning-based socio-demographic information identification from smart meter data. IEEE Trans. Smart Grid 2018, 10, 2593-2602. [CrossRef]

15. Liu, Z.; Jiang, L.; Osmani, M.; Demian, P. Building Information Management (BIM) and Blockchain (BC) for Sustainable Building Design Information Management Framework. Electronics 2019, 8, 724. [CrossRef]

16. Sittón-Candanedo, I.; Alonso, R.S.; García, Ó.; Muñoz, L.; Rodríguez-González, S. Edge Computing, IoT and Social Computing in Smart Energy Scenarios. Sensors 2019, 19, 3353. [CrossRef] [PubMed]

17. Lueth, K.L. Why the Internet of Things is called Internet of Things: Definition, history, disambiguation. IoT Anal. 2014, 19. Available online: https:/ /iot-analytics.com/internet-of-things-definition/ (accessed on 22 December 2019).

18. Alonso, R.S.; Tapia, D.I.; Bajo, J.; García, Ó.; de Paz, J.F.; Corchado, J.M. Implementing a hardware-embedded reactive agents platform based on a service-oriented architecture over heterogeneous wireless sensor networks. Ad Hoc Netw. 2013, 11, 151-166. [CrossRef]

19. Kethareswaran, V.; Ram, C.S. An Indian Perspective on the adverse impact of Internet of Things (IoT). Adv. Distrib. Comput. Artif. Intell. J. 2017, 6, 35-40. [CrossRef]

20. Chamoso, P.; González-Briones, A.; Rodríguez, S.; Corchado, J.M. Tendencies of Technologies and Platforms in Smart Cities: A State-of-the-Art Review. Wirel. Commun. Mob. Comput. 2018, 2018. [CrossRef]

21. Talari, S.; Shafie-Khah, M.; Siano, P.; Loia, V.; Tommasetti, A.; Catalão, J. A review of smart cities based on the internet of things concept. Energies 2017, 10, 421. [CrossRef]

22. Xu, L.D.; Xu, E.L.; Li, L. Industry 4.0: State of the art and future trends. Int. J. Prod. Res. 2018, 56, $2941-2962$. [CrossRef] 
23. Sittón-Candanedo, I.; Hernández-Nieves, E.; Rodríguez-González, S.; Santos-Martín, M.T.; González-Briones, A. Machine learning predictive model for industry 4.0. In Proceedings of the International Conference on Knowledge Management in Organizations, Zilina, Slovakia, 6-10 August 2018; pp. 501-510.

24. Sittón, I.; Alonso, R.S.; Hernández-Nieves, E.; Rodríguez-Gonzalez, S.; Rivas, A. Neuro-Symbolic Hybrid Systems for Industry 4.0: A Systematic Mapping Study. In Proceedings of the International Conference on Knowledge Management in Organizations, Zamora, Spain, 15-18 July 2019; pp. 455-465.

25. Chamoso, P.; Prieta, F.D.L. Swarm-Based Smart City Platform: A Traffic Application. Adv. Distrib. Comput. Artif. Intell. J. 2015, 4, 89-98. [CrossRef]

26. Kim, C.M.; Koh, S.J. Device management and data transport in IoT networks based on visible light communication. Sensors 2018, 18, 2741. [CrossRef] [PubMed]

27. Stojkoska, B.L.R.; Trivodaliev, K.V. A review of Internet of Things for smart home: Challenges and solutions. J. Clean. Prod. 2017, 140, 1454-1464. [CrossRef]

28. García, Ó.; Alonso, R.S.; Tapia, D.I.; Corchado, J.M. Electrical power consumption monitoring in hotels using the n-Core Platform. In Proceedings of the 2016 Clemson University Power Systems Conference (PSC), Clemson, SC, USA, 8-11 March 2016.

29. García, Ó.; Alonso, R.S.; Guevara, F.; De Paz, J.F.; Villarrubia, G.; Corchado, J.M.; Abrishambaf, O.; Vale, Z. Use of context-aware Social Computing to improve energy efficiency in public buildings. In Proceedings of the 2016 IEEE Symposium Series on Computational Intelligence (SSCI), Athens, Greece, 6-9 December 2016.

30. Kaur, N.; Sood, S.K. An energy-efficient architecture for the Internet of Things (IoT). IEEE Syst. J. 2017, 11, 796-805. [CrossRef]

31. Ai, Y.; Peng, M.; Zhang, K. Edge computing technologies for Internet of Things: A primer. Digit. Commun. Netw. 2018, 4, 77-86. [CrossRef]

32. Sittón-Candanedo, I.; Rodríguez, S. Pattern Extraction for the Design of Predictive Models in Industry 4.0. In Proceedings of the International Conference on Practical Applications of Agents and Multi-Agent Systems, Porto, Portugal, 21-23 June 2017; pp. 258-261.

33. Yu, W.; Liang, F.; He, X.; Hatcher, W.G.; Lu, C.; Lin, J.; Yang, X. A Survey on the Edge Computing for the Internet of Things. IEEE Access 2017, 6, 6900-6919, [CrossRef]

34. Sanchez-Iborra, R.; Sanchez-Gomez, J.; Skarmeta, A. Evolving IoT networks by the confluence of MEC and LP-WAN paradigms. Future Gener. Comput. Syst. 2018, 88, 199-208, [CrossRef]

35. Alonso, R.S.; Sittón-Candanedo, I.; Óscar García.; Prieto, J.; Rodríguez-González, S. An intelligent Edge-IoT platform for monitoring livestock and crops in a dairy farming scenario. Ad Hoc Netw. 2019. [CrossRef]

36. Mach, P.; Becvar, Z. Mobile edge computing: A survey on architecture and computation offloading. IEEE Commun. Surv. Tutor. 2017, 19, 1628-1656. [CrossRef]

37. Bittencourt, L.F.; Diaz-Montes, J.; Buyya, R.; Rana, O.F.; Parashar, M. Mobility-aware application scheduling in fog computing. IEEE Cloud Comput. 2017, 4, 26-35. [CrossRef]

38. Kitchenham, B.A.; Budgen, D.; Pearl Brereton, O. Using mapping studies as the basis for further research-A participant-observer case study. Inf. Softw. Technol. 2011, 53, 638-651. [CrossRef]

39. Petersen, K.; Vakkalanka, S.; Kuzniarz, L. Guidelines for conducting systematic mapping studies in software engineering: An update. Inf. Softw. Technol. 2015, 64, 1-18. [CrossRef]

40. Odun-Ayo, I.; Goddy-Worlu, R.; Geteloma, V.; Grant, E. A Systematic Mapping Study of Cloud, Fog, and Edge/Mobile Devices Management, Hierarchy Models and Business Models. Adv. Sci. Technol. Eng. Syst. J. 2018, 4, 91-101. [CrossRef]

41. Petersen, K.; Feldt, R.; Mujtaba, S.; Mattsson, M. Systematic Mapping Studies in Software Engineering. In Proceedings of the 12th International Conference on Evaluation and Assessment in Software Engineering, Bari, Italy, 26-27 June 2008; Volume 17, p. 10.

42. Keele, S. Guidelines for Performing Systematic Literature Reviews in Software Engineering; Ver. 2.3 EBSE Technical Report; EBSE: Rio de Janeiro, Brazil, 2007.

43. Heinz, M. Systematic Mapping Studies. Mainz: Universität Koblenz-Landau 2014. Available online: https: / / userpages.uni-koblenz.de/ laemmel/esecourse/slides/sms.pdf (accessed on 22 December 2019).

44. Edge Computing Consortium; Alliance of Industrial Internet. Edge Computing Reference Architecture 2.0; Technical Report; Edge Computing Consortium. 2017. Available online: http://en.ecconsortium.net/ Uploads / file/20180328/1522232376480704.pdf (accessed on 20 November 2018). 
45. INTEL-SAP. IoT Joint Reference Architecture from Intel and SAP; Technical Report; INTEL-SAP. 2018. Available online: https://www.intel.es/content/www/es/es/big-data/edge-computing-referencearchitecture.html (accessed on 21 January 2019).

46. FAR-EDGE Project. FAR-EDGE Project H2020. 2017. Available online: http://far-edge.eu/\{\#\}/ (accessed on 18 February 2019).

47. Tseng, M.; Canaran, T.E.; Canaran, L. Introduction to Edge Computing in IIoT; Technical Report; Industrial Internet Consortium. 2018. Available online: https:/ /www.iiconsortium.org/pdf/Introduction_to_Edge_Computing in_IloT_2018-06-18.pdf (accessed on 2 December 2018).

48. Shah, A.S.; Nasir, H.; Fayaz, M.; Lajis, A.; Shah, A. A review on energy consumption optimization techniques in IoT based smart building environments. Information 2019, 10, 108. doi:10.3390/info10030108. [CrossRef]

49. Fei, X.; Shah, N.; Verba, N.; Chao, K.M.; Sanchez-Anguix, V.; Lewandowski, J.; James, A.; Usman, Z. CPS data streams analytics based on machine learning for Cloud and Fog Computing: A survey. Future Gener. Comput. Syst. 2019, 90, 435-450, [CrossRef]

50. Portilla, J.; Mujica, G.; Lee, J.S.; Riesgo, T. The Extreme Edge at the Bottom of the Internet of Things: A Review. IEEE Sens. J. 2019, 19, 3179-3190. [CrossRef]

51. Gilbert, G.M.; Naiman, S.; Kimaro, H.; Bagile, B. A critical review of edge and fog computing for smart grid applications. In Proceedings of the IFIP Advances in Information and Communication Technology, Arlington, VA, USA, 11-12 March 2019; Volume 551, pp. 763-775.

52. Väänänen, O.; Hämäläinen, T. Requirements for Energy Efficient Edge Computing: A Survey. In Internet of Things, Smart Spaces, and Next Generation Networks and Systems. NEW2AN 2018, ruSMART 2018; Lecture Notes in Computer Science; Springer: Berlin/Heidelberg, Germany, 2018; Volume 11118, pp. 3-15.

53. Mao, Y.; You, C.; Zhang, J.; Huang, K.; Letaief, K.B. A Survey on Mobile Edge Computing: The Communication Perspective. IEEE Commun. Surv. Tutor. 2017, 19, 2322-2358. [CrossRef]

54. Samie, F.; Bauer, L.; Henkel, J. Edge Computing for Smart Grid: An Overview on Architectures and Solutions. In IoT for Smart Grids: Design Challenges and Paradigms; Springer International Publishing: Cham, Switzerland, 2019; pp. 21-42.

55. Wlodarczak, P. Smart Cities: Enabling Technologies for Future Living. In City Networks: Collaboration and Planning for Health and Sustainability; Springer International Publishing: Cham, Switzerland, 2017; pp. 1-16.

56. Tofan, D.; Galster, M.; Avgeriou, P.; Schuitema, W. Past and future of software architectural decisionsA systematic mapping study. Inf. Softw. Technol. 2014, 56, 850-872. [CrossRef]

57. Montalvillo, L.; Díaz, O. Requirement-driven evolution in software product lines: A systematic mapping study. J. Syst. Softw. 2016, 122, 110-143. [CrossRef]

58. Sittón-Candanedo, I. Edge Computing: A Review of Application Scenarios. In Proceedings of the International Symposium on Distributed Computing and Artificial Intelligence, Avila, Spain, 26-28 June 2019; pp. 197-200.

59. Khanna, A.; Arora, S.; Chhabra, A.; Bhardwaj, K.K.; Sharma, D.K. IoT architecture for preventive energy conservation of smart buildings. In Studies in Systems, Decision and Control; Springer: Singapore, 2019; Volume 206, pp. 179-208.

60. Zhou, Z.; Tan, L.; Xu, G. Blockchain and Edge Computing Based Vehicle-to-Grid Energy Trading in Energy Internet. In Proceedings of the 2nd IEEE Conference on Energy Internet and Energy System Integration, Beijing, China, 20-22 October 2018.

61. Alsmirat, M.A.; Jararweh, Y.; Obaidat, I.; Gupta, B.B. Internet of surveillance: a cloud supported large-scale wireless surveillance system. J. Supercomput. 2017, 73, 973-992. [CrossRef]

62. Liu, Y.; Yang, C.; Jiang, L.; Xie, S.; Zhang, Y. Intelligent Edge Computing for IoT-Based Energy Management in Smart Cities. IEEE Netw. 2019, 33, 111-117. [CrossRef]

63. Xia, C.; Li, W.; Chang, X.; Delicato, F.C.; Yang, T.; Zomaya, A. Edge-based energy management for smart homes. In Proceedings of the IEEE 16th International Conference on Dependable, Autonomic and Secure Computing, Athens, Greece, 12-15 August 2018; pp. 842-848.

64. Liu, C.H.; Gu, J.C. Modeling and Integrating PV Stations into IEC 61850 XMPP Intelligent Edge Computing Gateway. Energies 2019, 12, 1442. [CrossRef]

65. Wang, S.; Zhang, X.; Yan, Z.; Wang, W. Cooperative Edge Computing with Sleep Control under Non-uniform Traffic in Mobile Edge Networks. IEEE Internet Things J. 2018, 6, 4295-4306. [CrossRef]

66. Cicirelli, F.; Guerrieri, A.; Mercuri, A.; Spezzano, G.; Vinci, A. ITEMa: A methodological approach for cognitive edge computing IoT ecosystems. Future Gener. Comput. Syst. 2019, 92, 189-197. [CrossRef] 
67. Suárez-Albela, M.; Fraga-Lamas, P.; Fernández-Caramés, T.; Suárez-Albela, M.; Fraga-Lamas, P.; Fernández-Caramés, T.M. A Practical Evaluation on RSA and ECC-Based Cipher Suites for IoT High-Security Energy-Efficient Fog and Mist Computing Devices. Sensors 2018, 18, 3868. [CrossRef]

68. Ferrández-Pastor, F.J.; Mora, H.; Jimeno-Morenilla, A.; Volckaert, B. Deployment of IoT edge and fog computing technologies to develop smart building services. Sustainability 2018, 10, 3832. [CrossRef]

69. Zhou, Z.; Feng, J.; Tan, L.; He, Y.; Gong, J. An air-ground integration approach for mobile edge computing in IoT. IEEE Commun. Mag. 2018, 56, 40-47. doi:10.1109/MCOM.2018.1701111. [CrossRef]

70. Li, X.Q.; Zheng, S. Application of universal control platform in intelligent building. In Proceedings of the IGBSG 2018-2018 International Conference on Intelligent Green Building and Smart Grid, Sendai, Japan, 26-28 November 2018.

71. Pacheco, A.; Cano, P.; Flores, E.; Trujillo, E.; Marquez, P. A Smart Classroom Based on Deep Learning and Osmotic IoT Computing. In Proceedings of the 2018 Congreso Internacional de Innovacion y Tendencias en Ingenieria, Bogota, Colombia, 3-5 October 2018.

72. Chen, T.; Barbarossa, S.; Wang, X.; Giannakis, G.B.; Zhang, Z.L. Learning and Management for Internet of Things: Accounting for Adaptivity and Scalability. Proc. IEEE 2019, 107, 778-796. [CrossRef]

73. Liu, H.; Yang, L.T.; Lin, M.; Yin, D.; Guo, Y. A Tensor-Based Holistic Edge Computing Optimization Framework for Internet of Things. IEEE Netw. 2018, 32, 88-95. [CrossRef]

74. Sun, X.; Ansari, N. EdgeIoT: Mobile Edge Computing for the Internet of Things. IEEE Commun. Mag. 2016, 54, 22-29, [CrossRef]

75. Long, X.; Wu, J.; Chen, L. Energy-efficient offloading in mobile edge computing with edge-cloud collaboration. In Algorithms and Architectures for Parallel Processing. ICA3PP 2018; Lecture Notes in Computer Science; Springer: Berlin/Heidelberg, Germany, 2018; Volume 11336, pp. 460-475.

76. Amadeo, M.; Giordano, A.; Mastroianni, C.; Molinaro, A. On the integration of information centric networking and fog computing for smart home services. In Internet of Things; Springer International Publishing: Cham, Switzerland, 2019; pp. 75-93.

77. Li, Z.; Shahidehpour, M.; Liu, X. Cyber-secure decentralized energy management for IoT-enabled active distribution networks. J. Mod. Power Syst. Clean Energy 2018, 6, 900-917. [CrossRef]

78. Petri, I.; Zamani, A.R.; Balouek-Thomert, D.; Rana, O.; Rezgui, Y.; Parashar, M. Ensemble-based network edge processing. In Proceedings of the 11th IEEE/ACM International Conference on Utility and Cloud Computing, Zurich, Switzerland, 17-20 December 2018; pp. 133-142.

79. Galanis, I.; Perala, S.S.N.; Anagnostopoulos, I., Edge Computing and Efficient Resource Management for Integration of Video Devices in Smart Grid Deployments. In IoT for Smart Grids: Design Challenges and Paradigms; Springer International Publishing: Cham, Switzerland, 2019; pp. 115-132.

80. Chang, Y.C.; Lai, Y.H. Campus Edge Computing Network Based on IoT Street Lighting Nodes. IEEE Syst. J. 2018. [CrossRef]

81. Zhao, X.; Yang, K.; Chen, Q.; Peng, D.; Jiang, H.; Xu, X.; Shuang, X. Deep learning based mobile data offloading in mobile edge computing systems. Future Gener. Comput. Syst. 2019, 99, 346-355. [CrossRef]

82. Fang, W.; Ding, S.; Li, Y.; Zhou, W.; Xiong, N. OKRA: Optimal task and resource allocation for energy minimization in mobile edge computing systems. Wirel. Netw. 2019, 25, 2851-2867. [CrossRef]

83. Gu, L.; Cai, J.; Zeng, D.; Zhang, Y.; Jin, H.; Dai, W. Energy efficient task allocation and energy scheduling in green energy powered edge computing. Future Gener. Comput. Syst. 2019, 95, 89-99. [CrossRef]

84. El Ghmary, M.; Malki, M.O.C.; Hmimz, Y.; Chanyour, T. Energy and Computational Resources Optimization in a Mobile Edge Computing Node. In Proceedings of the 9th International Symposium on Signal, Image, Video and Communications, Rabat, Morocco, 27-30 November 2018; pp. 323-328.

85. Li, C.; Tang, J.; Luo, Y. Dynamic multi-user computation offloading for wireless powered mobile edge computing. J. Netw. Comput. Appl. 2019, 131, 1-15, [CrossRef]

86. Wang, F.; Xu, J.; Ding, Z. Multi-antenna NOMA for computation offloading in multiuser mobile edge computing systems. IEEE Trans. Commun. 2019, 67, 2450-2463. [CrossRef]

87. Zhao, M.; Zhou, K.; Zhao, M.; Zhou, K. Selective Offloading by Exploiting ARIMA-BP for Energy Optimization in Mobile Edge Computing Networks. Algorithms 2019, 12, 48. [CrossRef] 
88. Liu, B.; Huang, H.; Guo, S.; Chen, W.; Zheng, Z. Joint Computation Offloading and Routing Optimization for UAV-Edge-Cloud Computing Environments. In Proceedings of the 2018 IEEE SmartWorld, Ubiquitous Intelligence \& Computing, Advanced \& Trusted Computing, Scalable Computing \& Communications, Cloud \& Big Data Computing, Internet of People and Smart City Innovation (SmartWorld/SCALCOM/ UIC/ATC/CBDCom/IOP/SCI), Guangzhou, China, 8-12 October 2018; pp. 1745-1752.

89. Ku, Y.J.; Chiang, P.H.; Dey, S. Quality of service optimization for vehicular edge computing with solar-powered road side units. In Proceedings of the International Conference on Computer Communications and Networks, Hangzhou, China, 30 July-2 August 2018.

90. Jararweh, Y.; Al-Ayyoub, M.; Al-Quraan, M.; Tawalbeh, L.A.; Benkhelifa, E. Delay-aware power optimization model for mobile edge computing systems. Pers. Ubiquitous Comput. 2017, 21, 1067-1077. [CrossRef]

91. Casadei, R.; Fortino, G.; Pianini, D.; Russo, W.; Savaglio, C.; Viroli, M. A development approach for collective opportunistic Edge-of-Things services. Inf. Sci. 2019, 498, 154-169. [CrossRef]

92. Li, Y.; Orgerie, A.C.; Rodero, I.; Amersho, B.L.; Parashar, M.; Menaud, J.M. End-to-end energy models for Edge Cloud-based IoT platforms: Application to data stream analysis in IoT. Future Gener. Comput. Syst. 2018, 87, 667-678. [CrossRef]

93. Ismail, A.H.; El-Bahnasawy, N.A.; Hamed, H.F. AGCM: Active Queue Management-Based Green Cloud Model for Mobile Edge Computing. Wirel. Pers. Commun. 2019, 105, 765-785. [CrossRef]

94. Yang, L.; Zhang, H.; Li, M.; Guo, J.; Ji, H. Mobile edge computing empowered energy efficient task offloading in 5G. IEEE Trans. Veh. Technol. 2018, 67, 6398-6409. [CrossRef]

95. Briante, O.; Cicirelli, F.; Guerrieri, A.; Iera, A.; Mercuri, A.; Ruggeri, G.; Spezzano, G.; Vinci, A. A social and pervasive IoT platform for developing smart environments. In Internet of Things; Springer International Publishing: Cham, Switzerland, 2019; pp. 1-23.

96. Xu, X.; Li, Y.; Huang, T.; Xue, Y.; Peng, K.; Qi, L.; Dou, W. An energyaware computation offloading method for smart edge computing in wireless metropolitan area networks. J. Netw. Comput. Appl. 2019, 133, 75-85. [CrossRef]

97. Mocnej, J.; Miškuf, M.; Papcun, P.; Zolotová, I. Impact of edge computing paradigm on energy consumption in IoT. IFAC-PapersOnLine 2018, 51, 162-167. [CrossRef]

98. Ding, A.; Janssen, M. Opportunities for applications using 5G networks: Requirements, challenges, and outlook. In Proceedings of the Seventh International Conference on Telecommunications and Remote Sensing, Barcelona, Spain, 8-9 October 2018; pp. 27-34.

99. Leligou, H.C.; Zahariadis, T.; Sarakis, L.; Tsampasis, E.; Voulkidis, A.; Velivassaki, T.E. Smart Grid: A demanding use case for $5 \mathrm{G}$ technologies. In Proceedings of the 2018 IEEE International Conference on Pervasive Computing and Communications Workshops, Athens, Greece, 19-23 March 2018; pp. 215-220.

100. Rajith, A.; Soki, S.; Hiroshi, M. Real-time optimized HVAC control system on top of an IoT framework. In Proceedings of the 2018 3rd International Conference on Fog and Mobile Edge Computing, Barcelona, Spain, 23-26 April 2018; pp. 181-186.

101. Lujic, I.; De Maio, V.; Brandic, I. Adaptive Recovery of Incomplete Datasets for Edge Analytics. In Proceedings of the 2018 IEEE 2nd International Conference on Fog and Edge Computing, Washington DC, USA, 1-3 May 2018; pp. 1-10.

102. Liu, H.; Zhang, Y.; Yang, T. Blockchain-Enabled Security in Electric Vehicles Cloud and Edge Computing. IEEE Netw. 2018, 32, 78-83. [CrossRef]

103. Hou, W.; Ning, Z.; Guo, L. Green Survivable Collaborative Edge Computing in Smart Cities. IEEE Trans. Ind. Inform. 2018, 14, 1594-1605. [CrossRef]

104. Kiss, P.; Reale, A.; Ferrari, C.J.; Istenes, Z. Deployment of IoT applications on 5G edge. In Proceedings of the 2018 IEEE International Conference on Future IoT Technologies, Eger, Hungary, 18-19 January 2018.

105. Pan, J.; Yang, Z. Cybersecurity challenges and opportunities in the new edge computing+ IoT world. In Proceedings of the 2018 ACM International Workshop on Security in Software Defined Networks \& Network Function Virtualization, Tempe, AZ, USA, 21 March 2018; pp. 29-32.

106. Shukla, R.M.; Sengupta, S.; Chatterjee, M. Software-defined network and cloud-edge collaboration for smart and connected vehicles. In Proceedings of the Workshop Program of the 19th International Conference on Distributed Computing and Networking, Varanasi, India, 4-7 January 2018; p. 6.

107. Rajaei, H.; Mirzaei, F. IOT, Smart Homes and Zigbee Simulation. In Proceedings of the Communications and Networking Symposium, Rome, Italy, 19-21 June 2018; p. 8. 
108. Muñoz, R.; Mangues-Bafalluy, J.; Vilalta, R.; Verikoukis, C.; Alonso-Zarate, J.; Bartzoudis, N.; Georgiadis, A.; Payaró, M.; Perez-Neira, A.; Casellas, R.; et al. The CTTC 5G End-to-End Experimental Platform: Integrating Heterogeneous Wireless/Optical Networks, Distributed Cloud, and IoT Devices. IEEE Veh. Technol. Mag. 2016, 11, 50-63. [CrossRef]

109. Hua, M.; Huang, Y.; Sun, Y.; Wang, Y.; Yang, L. Energy optimization for Cellular-Connected UAV Mobile Edge Computing Systems. In Proceedings of the 2018 IEEE International Conference on Communication Systems (ICCS), Chengdu, China, 19-21 December 2018.

110. Alsuhli, G.; Khattab, A. A Fog-based IoT Platform for Smart Buildings. In Proceedings of the 2019 International Conference on Innovative Trends in Computer Engineering, Aswan, Egypt, 2-4 Febuary 2019; pp. 174-179.

111. Wu, D.; Wang, F.; Cao, X.; Xu, J. Wireless Powered User Cooperative Computation in Mobile Edge Computing Systems. In Proceedings of the 2018 IEEE Globecom Workshops, Abu Dhabi, United Arab Emirates, 9-13 December 2018.

112. Huang, B.; Li, X.; Li, D. Green virtualized edge computing: Successive Cournot model analysis. In AIP Conference Proceedings; American Institute of Physics Inc.: College Park, MD, USA, 2019; Volume 2073.

113. Zhang, H.; Chen, Z.; Wu, J.; Deng, Y.; Xiao, Y.; Liu, K.; Li, M.; Zhang, H.; Chen, Z.; Wu, J.; et al. Energy-Efficient Online Resource Management and Allocation Optimization in Multi-User Multi-Task Mobile-Edge Computing Systems with Hybrid Energy Harvesting. Sensors 2018, 18, 3140. [CrossRef]

114. Zhou, F.; Wu, Y.; Hu, R.Q.; Qian, Y. Computation rate maximization in UAV-Enabled wireless-powered mobile-edge computing systems. IEEE J. Sel. Areas Commun. 2018, 36, 1927-1941. [CrossRef]

115. Cao, X.; Xu, J.; Zhangt, R. Mobile Edge Computing for Cellular-Connected UAV: Computation Offloading and Trajectory Optimization. In Proceedings of the IEEE Workshop on Signal Processing Advances in Wireless Communications, Kalamata, Greece, 25-28 June 2018.

116. Rimal, B.P.; Maier, M.; Satyanarayanan, M. Experimental testbed for edge computing in fiber-wireless broadband access networks. IEEE Commun. Mag. 2018, 56, 160-167. [CrossRef]

117. Li, W.; Yang, T.; Delicato, F.C.; Pires, P.F.; Tari, Z.; Khan, S.U.; Zomaya, A.Y. On Enabling Sustainable Edge Computing with Renewable Energy Resources. IEEE Commun. Mag. 2018, 56, 94-101. [CrossRef]

118. Fan, Q.; Ansari, N. Application Aware Workload Allocation for Edge Computing-Based IoT. IEEE Internet Things J. 2018, 5, 2146-2153. [CrossRef]

119. Ahmadoh, E.; Lo'ai, A.T. Power consumption experimental analysis in smart phones. In Proceedings of the 2018 Third International Conference on Fog and Mobile Edge Computing (FMEC), Barcelona, Spain, 23-26 April 2018; pp. 295-299.

120. Alnoman, A.; Carvalho, G.H.; Anpalagan, A.; Woungang, I. Energy Efficiency on Fully Cloudified Mobile Networks: Survey, Challenges, and Open Issues. IEEE Commun. Surv. Tutor. 2017, 20, 1271-1291. [CrossRef]

121. Luo, C.; Salinas, S.; Li, M.; Li, P. Energy-Efficient Autonomic Offloading in Mobile Edge Computing. In Proceedings of the 2017 IEEE 15th Intl Conf on Dependable, Autonomic and Secure Computing, 15th Intl Conf on Pervasive Intelligence and Computing, 3rd Intl Conf on Big Data Intelligence and Computing and Cyber Science and Technology Congress (DASC/PiCom/DataCom/CyberSciTech), Orlando, FL, USA, 6-10 November 2017; pp. 581-588.

122. ur Rehman, M.H.; Liew, C.S.; Wah, T.Y.; Khan, M.K. Towards next-generation heterogeneous mobile data stream mining applications: Opportunities, challenges, and future research directions. J. Netw. Comput. Appl. 2017, 79, 1-24. [CrossRef]

123. Singh, S.P.; Nayyar, A.; Kumar, R.; Sharma, A. Fog computing: From architecture to edge computing and big data processing. J. Supercomput. 2019, 75, 2070-2105. [CrossRef]

124. Zheng, M.; Zhao, Y.; Zhang, X.; Xu, C.Z.; Li, X. A Feedback Prediction Model for Resource Usage and Offloading Time in Edge Computing. In Cloud Computing - CLOUD 2018; Lecture Notes in Computer Science; Springer: Berlin/Heidelberg, Germany, 2018; Volume 10967, pp. 235-247.

125. Mukhlif, F.; Noordin, K.A.B.; Mansoor, A.M.; Kasirun, Z.M. Green transmission for C-RAN based on SWIPT in 5G: A review. Wirel. Netw. 2019, 25, 2621-2649. [CrossRef]

126. Khattar, N.; Sidhu, J.; Singh, J. Toward energy-efficient cloud computing: A survey of dynamic power management and heuristics-based optimization techniques. J. Supercomput. 2019, 1-61. [CrossRef] 
127. Saravanan, K.; Julie, E.G.; Robinson, Y.H. Smart cities \& IoT: Evolution of applications, architectures \& technologies, present scenarios \& future dream. Intell. Syst. Ref. Libr. 2019, 154, 135-151. [CrossRef]

128. Bermbach, D.; Pallas, F.; Pérez, D.G.; Plebani, P.; Anderson, M.; Kat, R.; Tai, S. A Research Perspective on Fog Computing. In Service-Oriented Computing_ICSOC 2017 Workshops; Lecture Notes in Computer Science; Springer: Berlin/Heidelberg, Germany, 2018; Volume 10797, pp. 198-210.

(c) 2019 by the authors. Licensee MDPI, Basel, Switzerland. This article is an open access article distributed under the terms and conditions of the Creative Commons Attribution (CC BY) license (http:/ / creativecommons.org/licenses/by/4.0/). 